\title{
Caracterização estratigráfica dos depósitos sedimentares cenozoicos da Bacia do Ribeirão Sardinha, porção sul do Quadrilátero Ferrífero (MG), e estabelecimento de background geoquímico
}

\author{
The stratigraphic characterization of cenozoic sedimentary deposits of the Sardinha River Basin, \\ south portion of the Quadrilatero Ferrifero (MG), and the establishment of a geochemical background
}

\author{
Rayme Loureiro dos Santos ${ }^{1}$, Adivane Terezinha Costa $^{1}$ \\ 1 Universidade Federal de Ouro Preto - Campus Morro do Cruzeiro, CEP 35400-000, Ouro Preto, MG, BR \\ (raymeloureiro@gmail.com; adivanecosta@gmail.com)
}

Recebido em 10 de janeiro de 2017; aceito em 20 de abril de 2018

\begin{abstract}
Resumo
Este trabalho apresenta os resultados de levantamentos sedimentológicos e geoquímicos realizados na Bacia do Ribeirão Sardinha, porção sul do Quadrilátero Ferrífero, estado de Minas Gerais, Brasil. O estudo fundamentou-se na caracterização faciológica de perfis verticais de depósitos de barrancos e terraços e em dados mineralógicos e químicos relacionados às fácies identificadas e aos sedimentos atuais do afluente principal (barras e canal). A amostragem das fácies reconhecidas e dos sedimentos atuais totalizaram 54 amostras. A mineralogia foi obtida via difração de raios X e os dados geoquímicos, através da espectrometria de emissão óptica por plasma acoplado indutivamente (inductively coupled plasma optical emission spectrometry - ICP-OES). Os dados químicos foram submetidos a análises de componentes principais (principal component analysis — PCA) e utilizados para a aplicação da técnica Tukey inner fence (TIF), que possibilitou o estabelecimento de valores de background dos seguintes elementos: $\mathrm{Fe}, \mathrm{Mn}, \mathrm{Al}, \mathrm{Ba}, \mathrm{Cu}, \mathrm{Zn}, \mathrm{As}, \mathrm{Ni}, \mathrm{Cr}$ e Co. Os resultados de PCA indicam uma forte relação entre o Mn e os sedimentos atuais do Ribeirão Sardinha. Outros padrões geoquímicos foram realçados pelas altas concentrações de Fe e Mn, relacionadas aos sedimentos arenosos e cascalhosos de barras e canal, e pelos elevados teores de $\mathrm{Al}$ e $\mathrm{K}$ vinculados aos sedimentos finos constituintes dos depósitos de planícies de inundação e de lagoas de cheia. Os cálculos dos valores de background mostram um valor de referência elevado para o As $(32,89 \mathrm{mg} / \mathrm{kg}) \mathrm{e}$ anomalias referentes às altas concentrações de $\mathrm{Al}, \mathrm{Cu}, \mathrm{Zn}, \mathrm{Ni}$ e $\mathrm{Cr}$, sugerindo fontes geogênicas. Por outro lado, anomalias referentes aos valores elevados de $\mathrm{Co}, \mathrm{Ba}$ e Mn estão relacionadas a fontes antropogênicas.
\end{abstract}

Palavras-chave: Geoquímica de sedimentos fluviais; Valores de background; Anomalias; Fontes geogênica e antropogênica.

\begin{abstract}
This work presents the results of the sedimentological and geochemical studies carried out in the Sardinha River Basin, which is situated in the southern portion of the Quadrilátero Ferrífero, in the State of Minas Gerais (BR). This study was based on the faciological characterization of vertical profiles from cutbank and terrace deposits, mineralogical and chemical data related to identified facies, and to the active drainage sediments of the main tributary (bars and channel). Sampling of the recognized facies and current sediments totaled 54 samples. The mineralogy was obtained by X-ray diffraction and the geochemical data was obtained by inductively coupled plasma optical emission spectrometry (ICP-OES). Chemical data were submitted to a principal component analysis (PCA) and used for the application of the tukey inner fence (TIF) method, which allowed for the establishment of background values of the following elements: $\mathrm{Fe}, \mathrm{Mn}, \mathrm{Al}, \mathrm{Ba}, \mathrm{Cu}, \mathrm{Zn}, \mathrm{As}, \mathrm{Ni}, \mathrm{Cr}$ and Co. The PCA results indicate a strong relationship between Mn and current sediments from the Sardinha River. Others geochemical patterns were highlighted by high concentrations of Fe and Mn, related to sand and gravel sediments from bar and channel features, and by high levels of $\mathrm{Al}$ and $\mathrm{K}$, associated with fine sediments from the flood plains and oxbow lake deposits. The background results indicate a high background value for As $(32.89 \mathrm{mg} / \mathrm{kg})$ and anomalies that refer to high concentrations of $\mathrm{Al}, \mathrm{Cu}, \mathrm{Zn}, \mathrm{Ni}$ and $\mathrm{Cr}$, suggesting geogenic sources. Conversely, anomalies that refer to high values of $\mathrm{Co}, \mathrm{Ba}$ and $\mathrm{Mn}$ are related to anthropogenic sources.
\end{abstract}

Keywords: Geochemistry of fluvial sediments; Background values; Anomalies; Geogenic and anthropogenic sources. 


\section{INTRODUÇÃO}

O Quadrilátero Ferrífero é uma província mineral extremamente rica, principalmente em metais como ouro e ferro. Destaca-se na história econômica do Brasil devido à exploração aurífera que perdurou por 3 séculos e pela exploração do minério de ferro, que vem ocorrendo mais efetivamente desde 1913 (Roeser e Roeser, 2010), correspondendo a quase $70 \%$ da produção do país (DNPM, 2013). No cenário internacional, esse metal é exportado para o mercado europeu, China e Japão (Roeser e Roeser, 2010).

Durante o período colonial do Brasil, já existia a extração do ouro a montante da Bacia do Ribeirão Sardinha, foco deste estudo. A exploração do minério de ferro nessa área iniciouse, de forma rudimentar, em 1811. Em 1893 criou-se a usina de produção de ferro denominada Usina Wigg, dando início a uma nova fase de industrialização no distrito ouropretano de Miguel Burnier. Existem ainda relatos de que nesse mesmo ano iniciou-se a exploração de jazidas de manganês na região (Bohrer, 2011). Ao longo do tempo, diferentes grupos assumiram a mineradora de ferro, estando a intensidade de produção desse metal muito associada à administração de cada empresa, entretanto, sabe-se que em 2011 houve a ampliação da capacidade de produção na mina de Miguel Burnier, que vem sendo operada até a atualidade (CETEM, 2012).

A Bacia do Ribeirão Sardinha assenta-se sobre uma área geologicamente diversificada. Afloram rochas arqueanas correspondentes ao Complexo Bação (embasamento) e às metavulcanossedimentares do Supergrupo Rio das Velhas, rochas proterozoicas metavulcanossedimentares do Supergrupo Minas e rochas máficas intrusivas pós-Minas (Figura 1). Os granito-gnaisses associados ao Complexo Bação ocorrem no baixo curso do sistema fluvial e se limitam, na porção intermediária da bacia, com rochas do Supergrupo Rio das Velhas (xistos, filitos e quartzitos). As unidades do Supergrupo Minas, formadas por quartzitos, filitos, xistos, itabiritos (Formação Cauê) e dolomitos, ocupam a maior parte do alto e médio curso da bacia (Lobato et al., 2005). As supracrustais citadas encontram-se envolvidas pelo sinclinal Dom Bosco, estrutura resultante da tectônica extensional (colapso orogênico transamazônico) que gerou a arquitetura de domos e quilhas no Quadrilátero Ferrífero em 2,095 Ga (Alkmim e Marshak, 1998).

As mineralizações auríferas do Quadrilátero Ferrífero formaram-se a partir de fluidos hidrotermais ricos em ouro e em elementos traço associados que percolaram nas rochas supracrustais dessa província mineral. De acordo com Borba (2000), nas mineralizações de ouro correspondentes ao Supergrupo Rio das Velhas, participaram fluidos hidrotermais que carregaram, além do ouro, metais como Ag, As, $\mathrm{Sb}, \mathrm{Cu}, \mathrm{Pb}$ e Zn. Segundo Ribeiro (1998), o minério aurífero presente nas rochas do Supergrupo Minas também se encontra associado a metais pesados como $\mathrm{Ba}, \mathrm{As}, \mathrm{Hg}, \mathrm{Cd}$,
$\mathrm{Sb}$ e $\mathrm{Cu}$. De acordo com Costa et al. (2010), os metais Hg, $\mathrm{As}, \mathrm{Pb}, \mathrm{Zn}, \mathrm{Cu}, \mathrm{Cd}, \mathrm{Co}, \mathrm{Cr}$ e Ni encontrados nos sedimentos do Ribeirão do Carmo e do Rio Gualaxo do Norte, região SE do Quadrilátero Ferrífero, estão fortemente associados à atividade extrativo-mineral aurífera, inclusive à exploração de minas já exauridas.

No caso das formações ferríferas, Basílio (2005) apontou a ocorrência de vários elementos traço $(\mathrm{Ni}, \mathrm{Zn}, \mathrm{Cr}$, $\mathrm{Co}, \mathrm{Cu}, \mathrm{As}$ e $\mathrm{Pb}$ ) nos minérios de ferro das minas de Capanema, Alegria e Timbopeba, localizadas na porção SE do Quadrilátero Ferrífero.

De acordo com Selmi et al. (2009), os valores médios dos elementos traço presentes nos itabiritos e hematititos (rocha com mais de $98 \%$ de Fe) do Quadrilátero Ferrífero são inferiores aos teores encontrados nas formações ferríferas do mundo, entretanto, dos 13 elementos traço investigados pelos autores ( $\mathrm{V}, \mathrm{Co}, \mathrm{Ni}, \mathrm{Cu}, \mathrm{Zn}, \mathrm{Rb}, \mathrm{Sr}, \mathrm{Y}, \mathrm{Zr}, \mathrm{Nb}$, $\mathrm{Ba}$, Hf e Ta), notou-se concentrações maiores de $\mathrm{V}, \mathrm{Ba}$ e Co nos hematititos e de $\mathrm{Co}, \mathrm{V}, \mathrm{Ba}$ e Ni nos itabiritos.

Nesse contexto, considerando a variedade de elementos possivelmente tóxicos associada às unidades geológicas que constituem o Quadrilátero Ferrífero e a intensa prática extrativista decorrente na região, que pode intensificar os processos de disponibilização dos mesmos, vários trabalhos realizados nessa região têm apresentado como um dos objetivos a obtenção das concentrações de metais/elementos traço em sistemas fluviais, dentre eles Eleutério (1997), Oliveira (1998), Borba et al. (2000), Matschullat et al. (2000), Costa (2001, 2007), Costa et al. (2006, 2010), Rodrigues et al. $(2013,2014)$. O estudo dos depósitos de barrancos e terraços possibilita a reconstrução da história da poluição nos sistemas fluviais causada por elementos traço, uma vez que o grau de contaminação é registrado nas respectivas fácies depositadas ao longo do tempo (Rodrigues et al., 2013).

Considerando que só é possível detectar teores elevados de elementos em solos ou sedimentos baseando-se em valores considerados naturais, o estabelecimento dos valores de background (de referência) torna-se imprescindível para a definição de áreas contaminadas. De acordo com Matschullat et al. (2000), o background geoquímico é uma medida relativa que permite a distinção entre as concentrações naturais de elementos/compostos e concentrações antropogenicamente influenciadas em um conjunto de amostras.

O estabelecimento dos valores de background é de extrema importância por possibilitar a delimitação de áreas contaminadas (devido à presença significativa de elementos potencialmente perigosos), a distinção entre fontes geogênicas e antropogênicas e por permitir a compreensão dos possíveis processos de disponibilização de elementos em áreas com características geológicas específicas (Vicq et al., 2015).

O estudo da acumulação de metais pesados em sistemas fluviais tem sido uma preocupação dos órgãos ambientais, uma vez que esses elementos podem ocasionar a contaminação 
das águas e dos sedimentos que compõem esses ambientes. Altas concentrações de elementos tóxicos em planícies de inundação podem contaminar os recursos hídricos superficiais durante as inundações, e subsuperficiais, devido ao processo de recarga do aquífero. Esses depósitos, constituídos principalmente por sedimentos finos e matéria orgânica trazidos durante as épocas de cheia, tendem a ser férteis e por isso são muito utilizados para a agricultura. O uso dessas
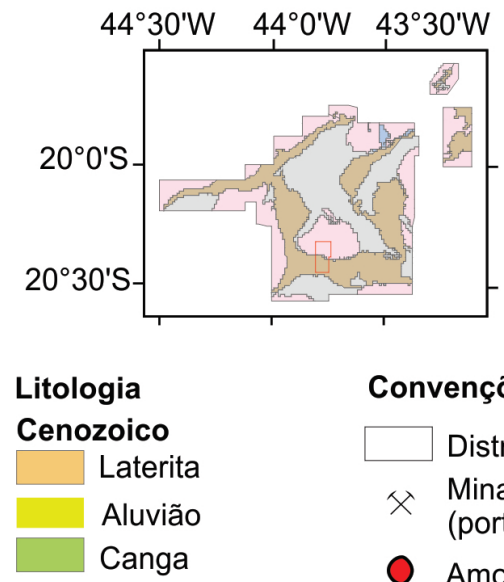

Paleoproterozoico
Supergrupo Minas
Grupo Piracicaba
(indiviso)
Formação
Cercadinho
Formação
Gandarela
Formação
Cauê
Formação
Batatal
Formação
Moeda
Arqueano
Supergrupo
Rio das Velhas

Rio das Velhas

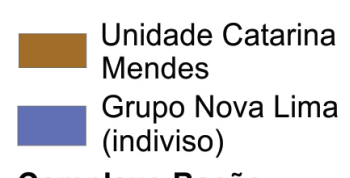

\section{Complexo Bação}

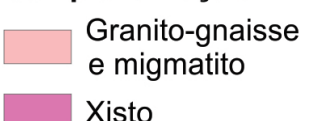

\section{Rocha intrusiva}

de idade incerta

Granodiorito

Dique de diabásio

\section{Convenções}

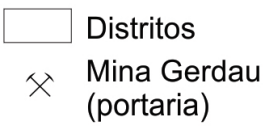

O Amostragem Bacia do

— Ribeirão Sardinha

A Sentido da drenagem

\section{Estruturas}

Falha de

A___ empurrão aproximada

Falha de

A empurrão definida

_. _ Falha indiscriminada

+ Sinclinal normal

\section{Atitudes}

\65 Lineação

43 Acamamento

Direção de

+ camadas verticais

$\varkappa^{85}$ Foliação

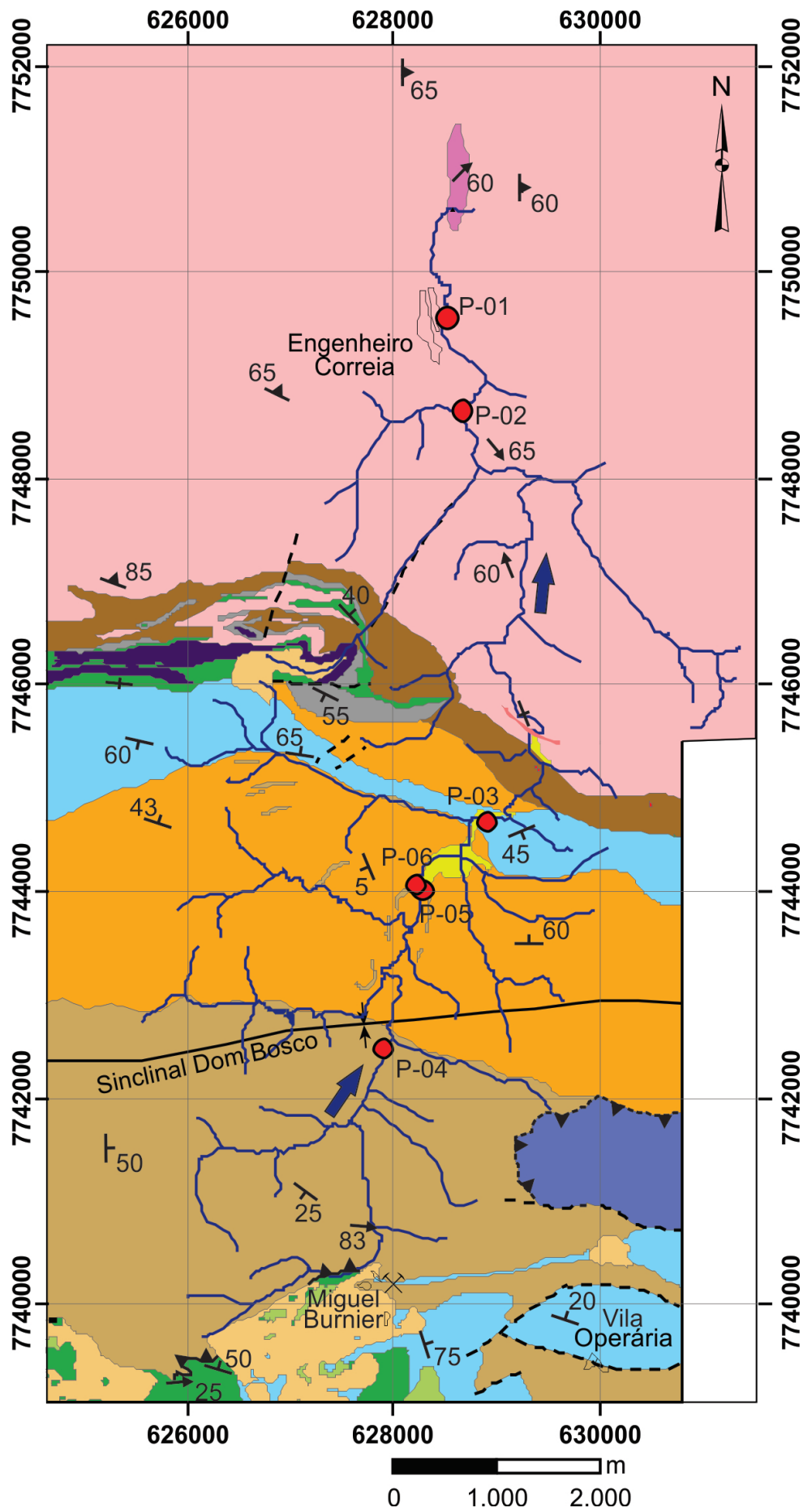

Fonte: Geologia: Lobato et al. (2005); hidrografia e distritos: IGA (1981a, 1981b, 1981c), cartas topográficas de Miguel Burnier, Itabirito e Cachoeira do Campo e DNPM (1962), carta topográfica Dom Bosco.

Figura 1. Mapa geológico com distribuição dos pontos de amostragem. 
áreas para a prática agrícola ou até mesmo como pastagens pode acarretar também a ingestão de poluentes pelo homem via cadeia alimentar (Costa, 2007).

Os principais objetivos deste trabalho foram:

- caracterizar os ambientes deposicionais relativos às associações de fácies de barrancos e terraços a partir da análise granulométrica, mineralógica e de estruturas sedimentares;

- detectar a variabilidade e disponibilidade de metais e elementos traço, através de análises químicas, presentes nos sedimentos de barras e canal e nas fácies reconhecidas nos barrancos e terraços aluviais;

- determinar os valores de background para os metais principais (ferro, manganês e alumínio) e elementos traço, tendo como base os conteúdos determinados nos terraços aluviais e, a partir dessas informações, quantificar as contribuições geogênicas e antropogênicas.

\section{MATERIAIS E MÉTODOS}

Foram coletadas 54 amostras de sedimentos em 6 sítios amostrais (Figura 1), sendo 13 retiradas dos depósitos de barras e canais atuais do rio e 41 correspondentes às fácies reconhecidas na caracterização estratigráfica de 4 perfis verticais de barrancos (BA, BB, BC e BD) e 4 de terraços (TA, TB, TC e TD).

O reconhecimento faciológico realizado a partir do levantamento dos perfis estratigráficos na escala $1 / 20$ baseou-se na caracterização textural, mineralógica e na identificação de estruturas sedimentares presentes nos barrancos e terraços. Todas as amostras foram submetidas a análises granulométricas, mineralógicas e químicas. As análises mineralógicas foram realizadas via difração de raios X, pelo difratômetro Panalytical, modelo Empyrean; e as análises químicas, através do espectrofotômetro de emissão óptica com plasma acoplado indutivamente (ICP-OES), marca Agilent 725. Para essa última, as amostras foram anteriormente submetidas ao processo de digestão parcial por água régia, metodologia proposta por Rauret et al. (2001). Utilizou-se, durante o processamento das amostras, o material de referência denominado reference lake sediment LKSD-2, coletado e preparado pelo Serviço Geológico do Canadá.

Os dados de assinatura geoquímica foram submetidos ao cálculo de correlações de Pearson via software Excel 2013, segundo diversas abordagens, ou seja, incluindo todas as amostras e separando-as por período de deposição (depósitos atuais, barrancos e terraços). O cálculo baseou-se nas concentrações dos 29 elementos químicos (As, Ba, $\mathrm{Bi}, \mathrm{Cd}, \mathrm{Co}, \mathrm{Cr}, \mathrm{Cu}, \mathrm{Li}, \mathrm{Mo}, \mathrm{Ni}$, $\mathrm{Sc}, \mathrm{Sr}, \mathrm{Th}, \mathrm{V}, \mathrm{Y}, \mathrm{Zn}, \mathrm{Be}, \mathrm{Mn}, \mathrm{Al}, \mathrm{Fe}, \mathrm{Ca}, \mathrm{K}, \mathrm{Mg}, \mathrm{Na}, \mathrm{Zr}, \mathrm{Pb}, \mathrm{P}, \mathrm{S}$ e Ti) lidos na análise de ICP-OES. Os elementos considerados comuns na região de estudo (e mais relevantes para este trabalho) e que apresentaram coeficientes de correlação maiores que 0,700 (Fe, Mn, Al, Ba, Cu, Zn, Ni, Cr, Co, V, K, Ti e As) foram selecionados para o tratamento estatístico que envolveu a análise de componentes principais (PCA) via software Minitab 18.
A determinação do número de componentes seguiu os critérios do modo R com utilização de uma matriz de correlação para a padronização dos dados. Essa técnica permitiu a identificação de padrões geoquímicos (através do agrupamento de elementos que apresentaram maior grau de similaridade) segundo diversas perspectivas, como época de deposição, pontos de amostragem, granulometria e tipos de depósitos.

Os valores de background foram determinados através da representação gráfica do tipo boxplot. A partir da metodologia Tukey inner fence (TIF) (Tukey, 1977; Reimann et al., 2005; Rodrigues, 2012), que propõe a multiplicação do intervalo interquartil por 1,5, foi possível separar os valores de background geoquímico dos outliers (Figura 2). Considerou-se como valor de referência o limite superior da "caixa" do gráfico boxplot produzido para cada elemento químico investigado. Para essa análise, preocupou-se em selecionar metais e elementos traço comuns na região de estudo, como $\mathrm{Fe}$, $\mathrm{Mn}, \mathrm{Al}, \mathrm{Ba}, \mathrm{Cu}, \mathrm{Zn}, \mathrm{As}, \mathrm{Ni}, \mathrm{Cr}$ e Co. O cálculo dos valores de background englobou os resultados químicos referentes às 54 amostras coletadas.

As idades de três depósitos de terraços via luminescência opticamente estimulada (LOE) foram obtidas através da utilização de dez alíquotas. Para a coleta das amostras, tubos de PVC de $30 \mathrm{~cm}$ de comprimento e $5 \mathrm{~cm}$ de diâmetro foram inseridos perpendicularmente a cada perfil, evitando-se a incidência de luz solar. Essa técnica, que fornece a datação de sedimentos com idades entre cem e um milhão de anos (Martins et al., 1999), é de extrema importância por servir de apoio ao estabelecimento dos valores de background.

\section{RESULTADOS}

\section{Caracterização estratigráfica}

A caracterização estratigráfica possibilitou a identificação das fácies sedimentológicas, presentes nos perfis dos terraços e barrancos investigados, e interpretação dos subambientes fluviais (Figuras 3 a 8 e Tabela 1). A Tabela 1 mostra uma síntese do levantamento faciológico realizado nos pontos de estudo,

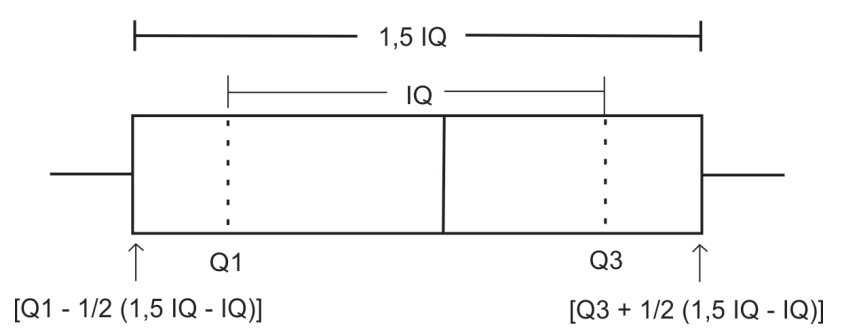

IQ: intervalo interquartil; Q1: primeiro quartil; Q3: terceiro quartil.

Figura 2. Metodologia aplicada para o cálculo do background geoquímico (Tukey, 1977; Rodrigues, 2012). 


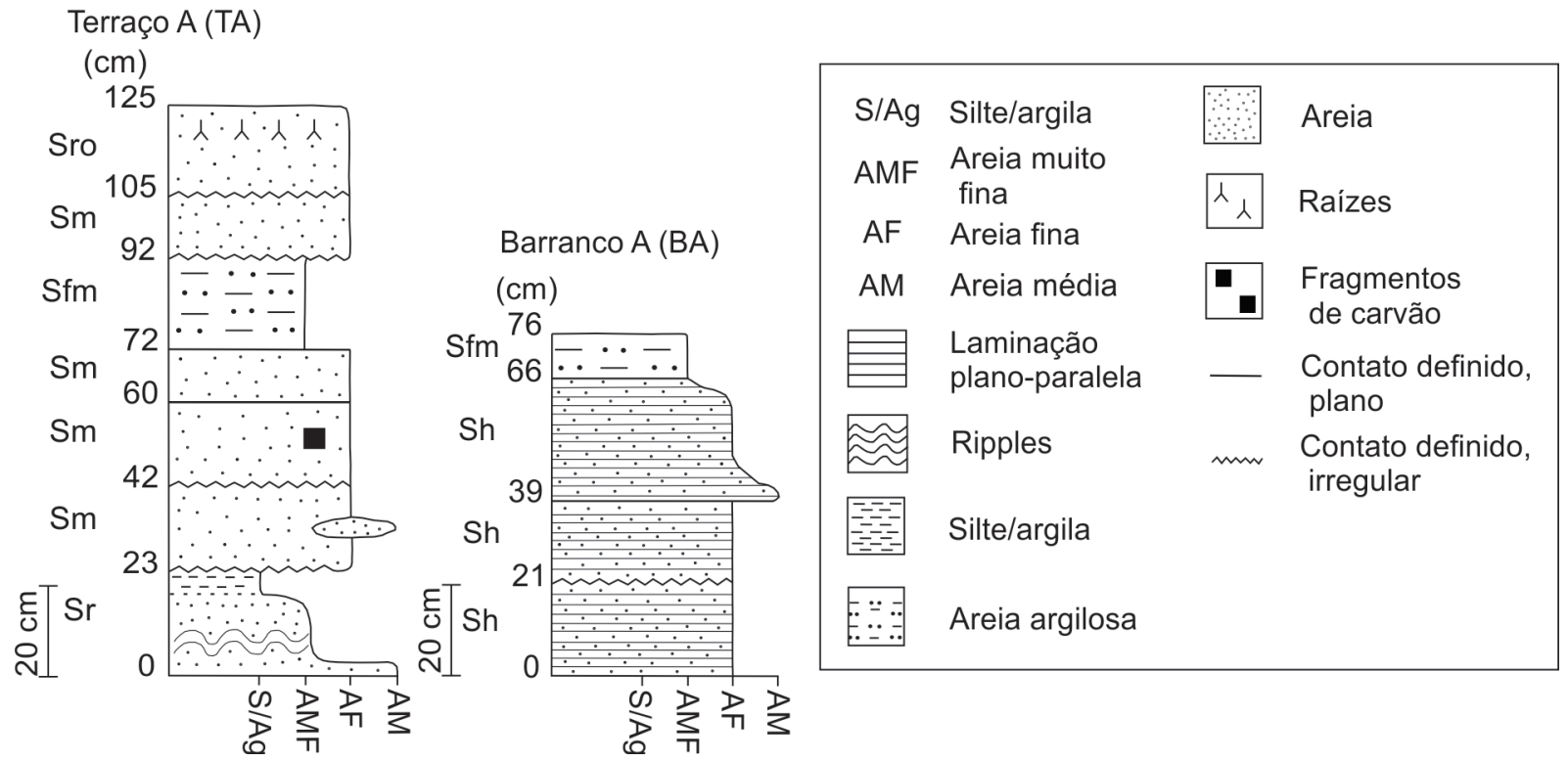

Figura 3. Colunas estratigráficas dos perfis analisados no ponto 01.

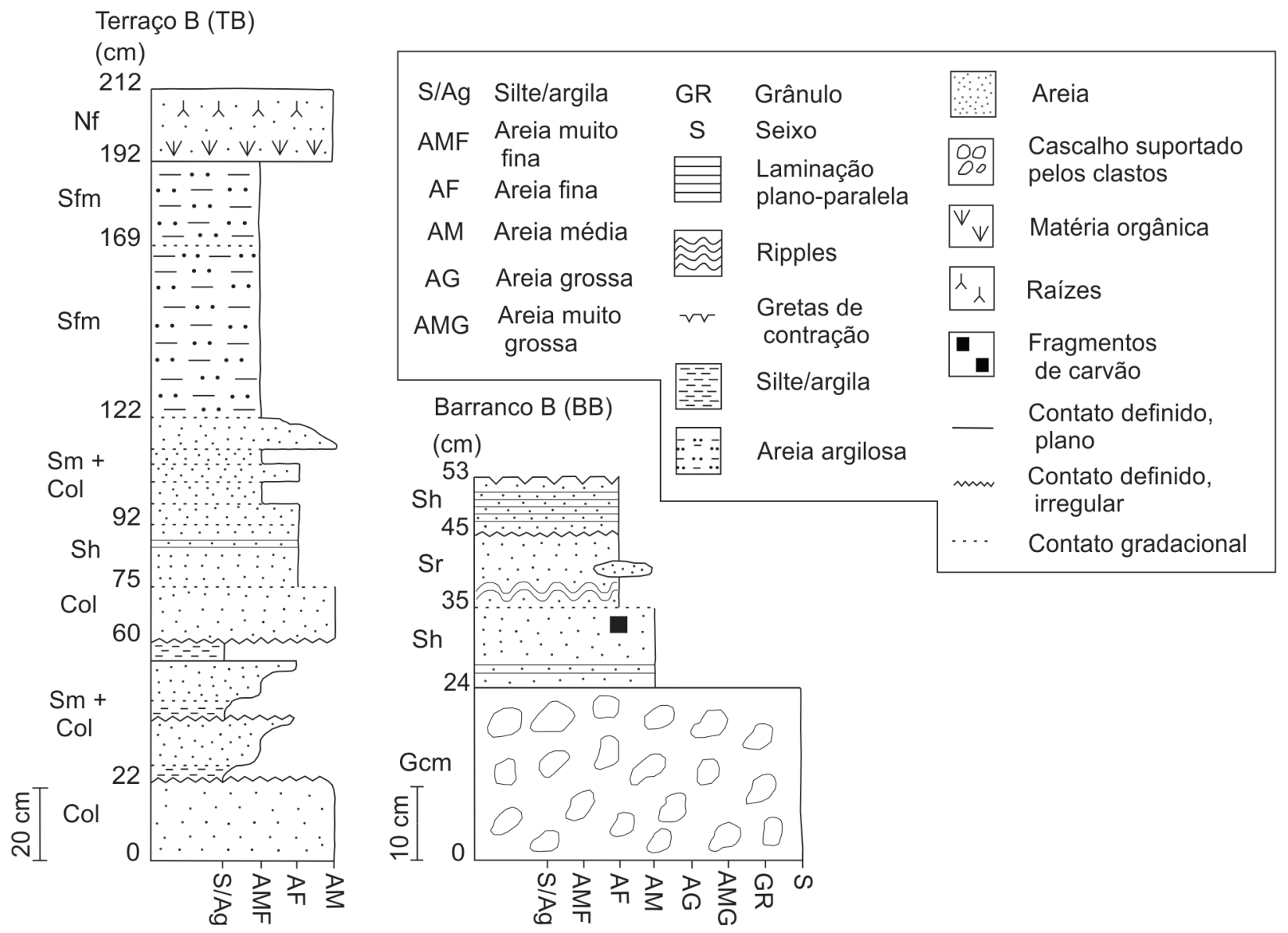

Figura 4. Colunas estratigráficas dos perfis analisados no ponto 02. 
baseado na nomenclatura de fácies sedimentares desenvolvida por Miall (1978), e dados mineralógicos obtidos via difração de raios $\mathrm{X}$ e atividades de campo. A seguir, encontram-se as descrições faciológicas detalhadas de todos os perfis analisados e as respectivas interpretações dos subambientes deposicionais.
As sucessões faciológicas dos perfis TA e BA localizamse no ponto 01 (Figuras 1 e 3 e Tabela 1). O perfil TA é constituído pelas fácies $\mathrm{Sr}, \mathrm{Sm}, \mathrm{Sfm}$ e Sro. Na base desse perfil, nota-se uma granodecrescência ascendente até $23 \mathrm{~cm}$, que apresenta estruturas do tipo ripples (marcas de onda) ( $\mathrm{Sr}$ ),

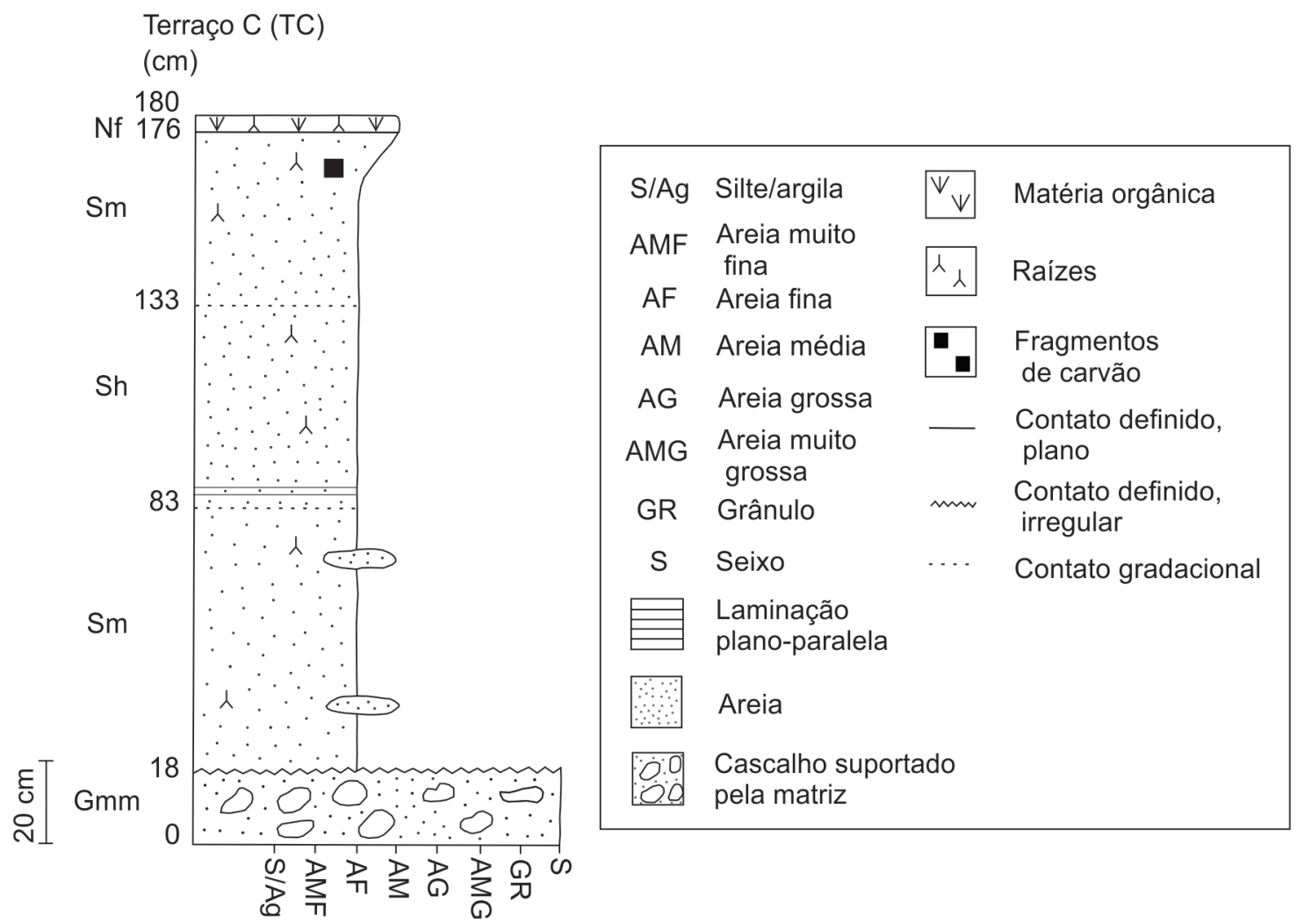

Figura 5. Coluna estratigráfica do perfil analisado no ponto 03.

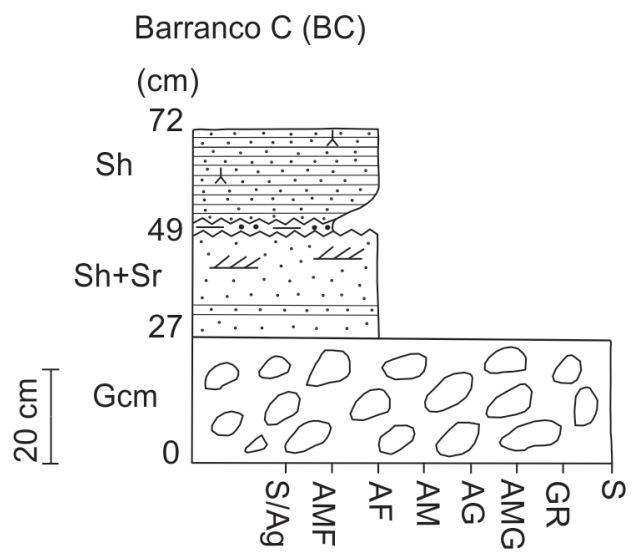

\begin{tabular}{|c|c|c|c|}
\hline $\mathrm{S} / \mathrm{Ag}$ & Silte/argila & $\begin{array}{ll}\Perp \\
\end{array}$ & $\begin{array}{l}\text { Laminação } \\
\text { cruzada }\end{array}$ \\
\hline AMF & $\begin{array}{l}\text { Areia muito } \\
\text { fina }\end{array}$ & & \\
\hline AF & Areia fina & & \\
\hline AM & Areia média & & Areia \\
\hline$A G$ & Areia grossa & & Cascalho suportado \\
\hline AMG & $\begin{array}{l}\text { Areia muito } \\
\text { grossa }\end{array}$ & & pelos clastos \\
\hline GR & Grânulo & $\lambda_{\lambda}$ & Raízes \\
\hline S & Seixo & & Contato definido, \\
\hline ह & $\begin{array}{l}\text { Laminação } \\
\text { plano-paralela }\end{array}$ & mon & $\begin{array}{l}\text { Contato definido, } \\
\text { irregular }\end{array}$ \\
\hline
\end{tabular}

Figura 6. Coluna estratigráfica do perfil analisado no ponto 04 . 
seguida por deposição de material silto-argiloso. Essa sequência foi interpretada como uma diminuição da velocidade do regime de fluxo no processo de formação de depósitos de barras. Os minerais identificados foram: quartzo, hematita, muscovita e caulinita. As fácies $\mathrm{Sm}$ (subdividida devido às diferentes tonalidades) e Sro também foram interpretadas como sequências de barras eventualmente recobertas por material de granulometria mais fina, proveniente da decantação em episódios de inundações (fácies Sfm). Em geral, os minerais presentes na fácies Sm foram: quartzo, muscovita, caulinita e hematita. Mais ao topo do perfil (a partir de $72 \mathrm{~cm}$ ) ocorreram apenas os três primeiros minerais. A sucessão do barranco BA é constituída pelas fácies Sh e $\mathrm{Sfm}$. Na fácies Sh (subdividida devido às diferentes colorações), observam-se laminações plano-paralelas relacionadas a um aumento do regime de fluxo ocorrido durante inundações instantâneas no processo de formação de barras fluviais (Miall, 1992). Os principais minerais diagnosticados foram quartzo, muscovita e caulinita. Entre 39 e $66 \mathrm{~cm}$, também detectou-se ilmenita. A fácies Sfm é decorrente da posterior diminuição do fluxo energético que possibilitou a deposição da sequência areno-argilosa em ambiente de planície de inundação. Nessa, foram encontrados minerais como quartzo, muscovita, caulinita e goethita.

As sucessões faciológicas dos perfis TB e BB localizam-se no ponto 02 (Figuras 1 e 4; Tabela 1). No perfil TB foram identificadas as fácies $\mathrm{Col}, \mathrm{Sm}+\mathrm{Col}, \mathrm{Sh}, \mathrm{Sfm}$ e Nf. A fácies Col foi interpretada como depósito coluvionar por apresentar composição rica em caulinita e coloração rosada, características típicas de solos residuais de rochas granito-gnáissicas que ocorrem nas adjacências desse perfil. Já a fácies $\mathrm{Sm}+\mathrm{Col}$ corresponde a uma alternância de níveis de origem coluvionar e de sedimentos de barras. Frequentemente o colúvio ocorre intercalado a sedimentos mais finos que foram depositados sob um regime de fluxo fluvial menos energético. As fácies constituídas por material coluvionar geralmente apresentaram, na difração de raios $\mathrm{X}$, minerais como quartzo, caulinita, muscovita e gibsita. As fácies Sh e Sfm representam, respectivamente, depósitos de barras com laminação plano-paralela e de planície de inundação. Na primeira, foram observados muscovita, caulinita, quartzo e gibsita; na segunda, além desses três primeiros, detectou-se também a hematita. A fácies Nf é interpretada como prováveis depósitos

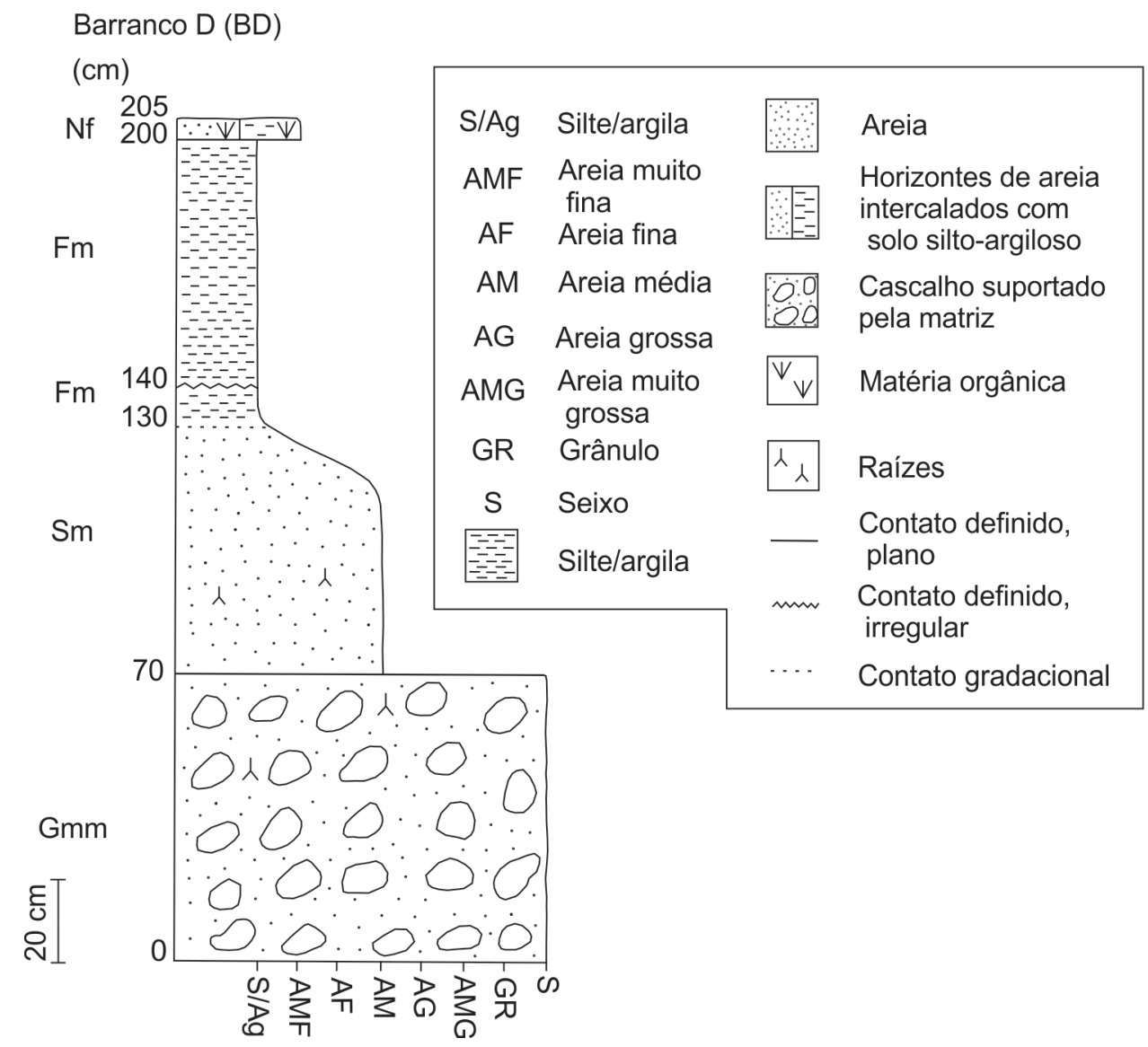

Figura 7. Coluna estratigráfica do perfil analisado no ponto 05. 
coluvionares que se encontram sob atuação de processos pedogenéticos. As idades da base (fácies Col, a $5 \mathrm{~cm}$ da base) e do topo (fácies Sfm, a $127 \mathrm{~cm}$ da base) desse terraço, obtidas via luminescência opticamente estimulada, foram de $32.000 \pm 3.400$ e $1.600 \pm 235$ anos atrás, respectivamente. O perfil BB é constituído pelas fácies $\mathrm{Gcm}$, Sh e Sr. A primeira, que ocorre na base do perfil, corresponde a um depósito de canal e as seguintes, sequências arenosas com alternância de estruturas como laminação plano-paralela, ripples e laminação plano-paralela, evidenciam alterações na velocidade do fluxo do rio, que variou entre

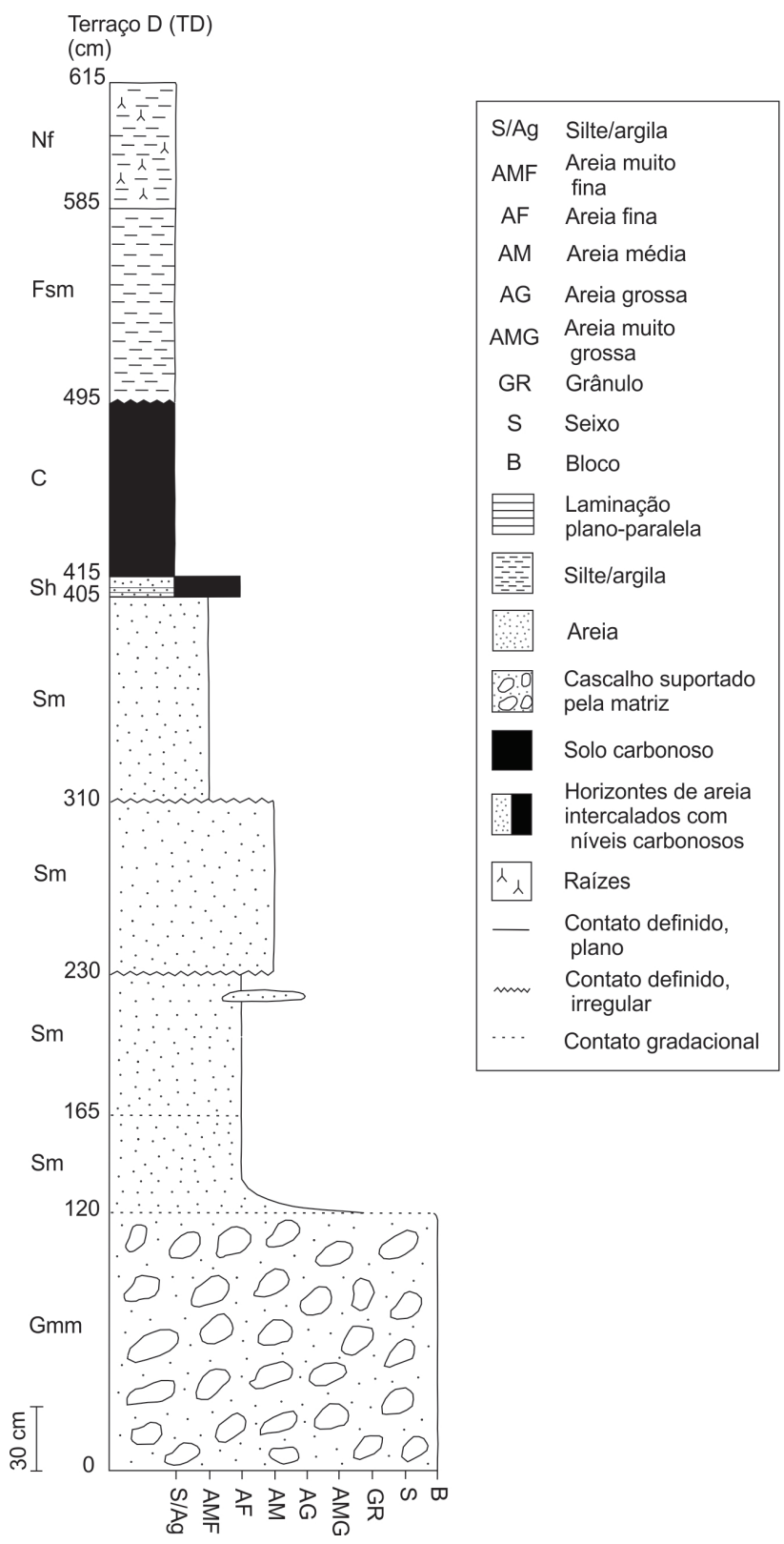

Figura 8. Coluna estratigráfica do perfil analisado no ponto 06. superior, inferior e superior, respectivamente, durante a formação dos depósitos de barras. Na fácies $\mathrm{Gcm}$ foram diagnosticados minerais como quartzo, hematita, caulinita, gibsita e magnetita. A fácies Sh apresentou caulinita, muscovita, quartzo, goethita, hematita e feldspato, entre 24 e $35 \mathrm{~cm}$, e quartzo, biotita e dolomita, entre 45 e 53 centímetros. Na fácies $\mathrm{Sr}$ foram identificados quartzo, hematita e flogopita. Vale ressaltar que essa sequência depositou-se sobre parte dos depósitos de canal associados ao terraço TB, que se encontravam nas margens do canal do Ribeirão Sardinha.

O terraço TC encontra-se no ponto 03 (Figuras 1 e 5; Tabela 1). Essa sucessão é formada pelas fácies $\mathrm{Gmm}, \mathrm{Sm}$, Sh e Nf. A fácies Gmm é interpretada como um depósito de leito do rio e as demais, como depósitos de barras sobrejacentes. As laminações plano-paralelas na fácies Sh não são persistentes e ocorrem somente na base desse estrato, portanto podem ser interpretadas como um ligeiro aumento da energia de fluxo, que apresentou pouca durabilidade. Outra possibilidade seria a existência de um hiato deposicional causado pela erosão dessa sequência. Em geral, as fácies mostraram minerais como quartzo, caulinita, muscovita e hematita. A fácies Sh apresentou ilmenita ao invés de hematita. A idade da porção inferior desse terraço (fácies $\mathrm{Sm}$, a $20 \mathrm{~cm}$ da base), via luminescência opticamente estimulada, foi de $6.200 \pm 1.000$ anos atrás.

$\mathrm{O}$ barranco BC, que se localiza no ponto 04 (Figuras $1 \mathrm{e}$ 6; Tabela 1), é constituído pelas fácies $\mathrm{Gcm}, \mathrm{Sh}+\mathrm{Sr}$ e $\mathrm{Sh}$. A primeira corresponde a depósitos de canal e as demais, à formação de barras. As estruturas formadas nessas últimas fácies, laminações paralelas e cruzadas, correspondem a um regime de fluxo superior que, de acordo com Miall (1988a, 1988b, 2006), podem ocorrer em barras associadas ao canal fluvial. Todas as fácies evidenciaram quartzo e muscovita. Além desses minerais, a fácies $\mathrm{Gcm}$ apresentou caulinita $\mathrm{e}$ goethita e a fácies Sh, caulinita.

$\mathrm{O}$ barranco BD, localizado no ponto 05 (Figuras 1 e 7; Tabela 1), representa uma sequência típica de sedimentação fluvial, já que mostra uma sucessão bem marcada, formada por cascalhos na base (fácies $\mathrm{Gmm}$ ), sedimentos arenosos na parte intermediária do perfil (fácies $\mathrm{Sm}$ ) e material silto-argiloso no topo (fácies Fm e Nf). Essa sequência pode ser interpretada como depósitos de canal que foram sobrepostos por barras e depósitos de planície de inundação, respectivamente. A fácies $\mathrm{Gmm}$ apresentou minerais como quartzo, muscovita e caulinita, enquanto a Sm evidenciou minerais como quartzo, muscovita, magnetita e hematita. Na fácies Fm observou-se minerais como quartzo, mica, caulinita e gibsita. De acordo com Walker (1992), esse perfil representa um ciclo de granodecrescência ascendente típico de regime fluvial meandrante.

O terraço TD posiciona-se no ponto 06 (Figuras $1 \mathrm{e}$ 8 e Tabela 1) e exibe as seguintes fácies: $\mathrm{Gmm}, \mathrm{Sm}, \mathrm{Sh}$, 
C, Fsm e Nf. Partindo-se da base do perfil, essa sucessão representa, primeiramente, a formação de depósitos de leito do rio (fácies $\mathrm{Gmm}$ ) que foram sobrepostos por barras (fácies $\mathrm{Sm}$ ). As fácies $\mathrm{Sh}$ e $\mathrm{C}$ retratam uma possível migração do canal. A primeira representa a transição do processo de abandono do canal, já que exibe laminações horizontais constituídas por finas camadas alternadas de areia quartzosa e silte carbonoso, indicando a existência de uma variação da energia de fluxo, que em um momento favorece a sedimentação de material fino e em outro, de material arenoso. Já a fácies $\mathrm{C}$, de natureza carbonosa, provavelmente depositou-se sobre o canal já abandonado onde se formou uma lagoa de cheia. A espessa camada denominada Sm indica que a margem do rio foi assoreada gradativamente, promovendo assim o lento abandono do canal, processo comum em rios meandrantes (Miall, 2006). Provavelmente, a fácies Fsm foi precipitada na lagoa de cheia em um outro período de inundação. A fácies Nf é resultante de processos pedogenéticos atuantes no topo da fácies Fsm. Todas as fácies apresentaram minerais como quartzo, muscovita e caulinita, além desses, a fácies $\operatorname{Sm}(1,20$ a $1,65 \mathrm{~cm})$ também apresentou goethita. A idade da porção intermediária desse terraço (fácies $\mathrm{Sm}$, a $285 \mathrm{~cm}$ da base), via luminescência opticamente estimulada, foi de $10.000 \pm 1.300$ anos atrás.

Tabela 1. Resumo da caracterização estratigráfica realizada na área de estudo.

\begin{tabular}{|c|c|c|c|c|}
\hline Ponto & Perfis & $\begin{array}{c}\text { Fácies } \\
\text { identificadas* }\end{array}$ & Minerais predominantes ${ }^{\star \star}$ & Interpretação dos depósitos \\
\hline \multirow{6}{*}{ P-01 } & \multirow{4}{*}{ Terraço } & Sro & Quartzo, muscovita, caulinita & Barras \\
\hline & & $\mathrm{Sm}$ & Quartzo, hematita, muscovita, caulinita & Barras \\
\hline & & Sfm & Quartzo, muscovita, caulinita & Barras \\
\hline & & $\mathrm{Sr}$ & Quartzo, hematita, muscovita, caulinita & Barras \\
\hline & \multirow{2}{*}{ Barranco } & Sfm & Quartzo, muscovita, caulinita, goethita & Planície de inundação \\
\hline & & Sh & Quartzo, muscovita, caulinita, ilmenita & Barras \\
\hline \multirow{8}{*}{ P-02 } & \multirow{5}{*}{ Terraço } & $\mathrm{Nf}^{\star \star \star}$ & Quartzo, óxidos de Fe & Solo resultante de alteração pedogenética \\
\hline & & Sfm & Quartzo, hematita, muscovita, caulinita & Planície de inundação \\
\hline & & $\mathrm{Sm}+\mathrm{Col}$ & $\begin{array}{l}\text { Quartzo, muscovita, caulinita, hematita, } \\
\text { gibsita }\end{array}$ & Alternância barras/colúvio \\
\hline & & Sh & Muscovita, caulinita, quartzo, gibsita & Barras \\
\hline & & Col & Quartzo, caulinita, muscovita, gibsita & Colúvio \\
\hline & \multirow{3}{*}{ Barranco } & Sh & $\begin{array}{l}\text { Quartzo, caulinita, muscovita, goethita, } \\
\text { hematita, feldspato, biotita }\end{array}$ & Barras/Planície de inundação \\
\hline & & $\mathrm{Sr}$ & Quartzo, hematita, flogopita & Barras \\
\hline & & Gcm & Quartzo, muscovita, caulinita, hematita & Canal \\
\hline \multirow{4}{*}{ P-03 } & \multirow{4}{*}{ Terraço } & $N f^{\star \star \star}$ & Quartzo, óxidos de Fe & Barras \\
\hline & & Sm & Quartzo, hematita, caulinita, muscovita & Barras \\
\hline & & Sh & Quartzo, ilmenita, muscovita, caulinita & Barras \\
\hline & & $\mathrm{Gmm}$ & Caulinita, muscovita, quartzo, hematita & Canal \\
\hline \multirow{3}{*}{ P-04 } & \multirow{3}{*}{ Barranco } & Sh & Muscovita, quartzo, caulinita & Barras \\
\hline & & $\mathrm{Sh}+\mathrm{Sr}$ & Muscovita, quartzo & Barras \\
\hline & & Gcm & Quartzo, muscovita, caulinita, goethita & Canal \\
\hline \multirow{4}{*}{ P-05 } & \multirow{4}{*}{ Barranco } & $N f^{\star \star \star}$ & Quartzo, óxidos de Fe & Solo resultante de alteração pedogenética \\
\hline & & $\mathrm{Fm}$ & Quartzo, muscovita, fengita, caulinita, gibsita & Planície de inundação \\
\hline & & $\mathrm{Sm}$ & Quartzo, magnetita, hematita, muscovita & Barras \\
\hline & & Gmm & Quartzo, muscovita, caulinita & Canal \\
\hline \multirow{6}{*}{ P-06 } & \multirow{6}{*}{ Terraço } & $N f^{\star \star \star}$ & Quartzo, óxidos de Fe & Solo resultante de alteração pedogenética \\
\hline & & Fsm & Quartzo, muscovita, caulinita & Lagoa de cheia \\
\hline & & C & Quartzo, muscovita, caulinita & Lagoa de cheia \\
\hline & & Sh & Quartzo, muscovita, caulinita & Barras \\
\hline & & Sm & Quartzo, muscovita, caulinita, goethita & Barras \\
\hline & & $\mathrm{Gmm}$ & Quartzo, muscovita, caulinita & Canal \\
\hline
\end{tabular}

*Descrição de fácies baseada nos conceitos de Miall (1978): C: argila carbonosa, Col: colúvio, Fm: argila siltosa maciça, Fsm: silte argiloso maciço, Gcm: cascalho maciço suportado pelos clastos, Gmm: cascalho maciço suportado pela matriz, Nf: neossolo flúvico, Sfm: areia argilosa maciça, Sh: areia com laminação planoparalela, Sm: areia maciça, Sr: areia com ripples ou laminação cruzada, Sro: areia com raízes. ${ }^{* *}$ Mineralogia obtida via difração de raios X e observações de campo. ${ }^{* \star *}$ Fácies não amostrada para análises laboratoriais. 


\section{Características dos sedimentos correspondentes ao sistema fluvial atual}

As amostras dos sedimentos associados ao sistema fluvial atual, juntamente com as fácies amostradas dos barrancos e dos terraços, possibilitaram a comparação geoquímica entre depósitos formados em épocas diferentes sob os mesmos processos sedimentares. Os tipos de depósitos amostrados em cada ponto, bem como suas características granulométricas e mineralógicas (via difração de raios X), podem ser visualizados na Tabela 2.

\section{Análise química dos sedimentos}

As concentrações químicas dos elementos considerados mais comuns na região de estudo e relevantes para este trabalho, referentes a cada amostra coletada, podem ser visualizadas nas Tabelas 3 e 4.

\section{Correlação de Pearson}

Os pares de elementos que apresentaram correlações mais significativas e seus respectivos coeficientes de correlação podem ser visualizados na Tabela 5.

\section{Análises geoquímicas}

A PCA, que englobou todas as amostras coletadas e os elementos envolvidos nas principais correlações de Pearson obtidas, indicou uma porcentagem de variância de $37,3 \%$ para o componente 1 e de $29,8 \%$ para o componente 2. Essas proporções estão relacionadas às maiores variabilidades das concentrações de $\mathrm{Mn}$ e V entre as amostras, respectivamente.
A partir dos gráficos de PCA foi possível observar padrões geoquímicos relacionados ao período de deposição, ao posicionamento dos pontos de amostragem (Figura 9), às frações granulométricas e aos tipos de depósitos sedimentares (Figura 10).

Na Figura 9 observou-se que os depósitos atuais apresentaram claramente maiores concentrações de As, Ba e Mn. Já os mais antigos (barrancos e terraços) mostraram grandes variações no conteúdo dos elementos investigados. Considerando os pontos de amostragem, ficou evidente a estreita relação entre o ponto 4 e teores elevados de As, Ba e Mn. Os outros pontos tenderam a apresentar maior variabilidade na composição química. Vale ressaltar que as características do ponto 4 refletem a proximidade com as rochas itabiríticas, fontes de $\mathrm{Mn}$, e a presença de um barramento localizado a cerca de $40 \mathrm{~m}$ a jusante dos depósitos amostrados, o qual foi construído para a viabilização do acesso. Essa obra de intervenção, composta por quatro tubos com aproximadamente um metro de diâmetro, promove maior retenção de sedimentos e consequentemente maior acumulação de determinados elementos químicos, sobretudo aqueles associados aos sedimentos de maior granulometria, mais facilmente retidos pela estrutura.

Na Figura 10 observa-se que as maiores concentrações de $\mathrm{Al}, \mathrm{K}$ e $\mathrm{V}$ estão relacionadas aos sedimentos mais finos (silte e argila). Esses materiais estão muito associados às planícies de inundação, às lagoas de cheia e aos depósitos constituídos por material coluvionar. É importante lembrar que esses últimos foram assim denominados no registro faciológico por apresentar aspecto semelhante aos solos residuais de granito-gnaisses, rochas aflorantes nas redondezas do local onde tais depósitos foram identificados. Outro padrão geoquímico bem marcado está vinculado às concentrações dos demais elementos, que apresentaram forte

Tabela 2. Principais características dos sedimentos amostrados do sistema fluvial atual.

\begin{tabular}{|c|c|c|c|}
\hline Ponto & Tipo de depósito & $\begin{array}{l}\text { Granulometria } \\
\text { predominante }\end{array}$ & Principais minerais \\
\hline \multirow{3}{*}{ P-01 } & Canal & Areia/cascalho & Muscovita, quartzo, caulinita, gibsita, goethita \\
\hline & Barra em pontal & Areia/cascalho & Muscovita, caulinita, quartzo \\
\hline & Barra longitudinal & Areia/cascalho & Muscovita, quartzo, caulinita, gibsita \\
\hline \multirow{3}{*}{ P-02 } & Canal & Areia & \multirow{3}{*}{$\begin{array}{c}\text { Muscovita, quartzo, caulinita, gibsita } \\
\text { Caulinita, quartzo, muscovita, goethita, magnetita } \\
\text { Muscovita, quartzo, caulinita, gibsita, goethita, } \\
\text { hematita }\end{array}$} \\
\hline & Barra em pontal & Areia/cascalho & \\
\hline & Barra longitudinal & Areia & \\
\hline P-03 & $\begin{array}{c}\text { Canal } \\
\text { Barra em pontal }\end{array}$ & $\begin{array}{l}\text { Areia/cascalho } \\
\text { Areia }\end{array}$ & $\begin{array}{l}\text { Quartzo, caulinita, muscovita, hematita } \\
\text { Gibsita, quartzo, muscovita, caulinita }\end{array}$ \\
\hline \multirow{3}{*}{ P-04 } & Canal & Areia/cascalho & Fengita, quartzo \\
\hline & Barra em pontal & Areia/cascalho & Quartzo, caulinita, muscovita \\
\hline & Barra longitudinal & Areia & Muscovita, quartzo, feldspato, caulinita, goethita \\
\hline $\mathrm{P}-05^{\star}$ & $\begin{array}{c}\text { Barra longitudinal/barra em } \\
\text { pontal }\end{array}$ & Areia & Caulinita, muscovita, quartzo \\
\hline P-06 & Canal & Cascalho/areia & Caulinita, muscovita, quartzo \\
\hline
\end{tabular}

*Neste ponto detectou-se um processo de migração do canal fluvial que provocou a mudança do depósito de barra longitudinal para barra em pontal. 
Tabela 3. Resultados químicos das amostras coletadas nos pontos 01 e 02.

\begin{tabular}{|c|c|c|c|c|c|c|c|c|c|c|c|c|c|}
\hline \multirow{2}{*}{ Amostra } & As & $\mathrm{Ba}$ & Co & $\mathrm{Cr}$ & $\mathrm{Cu}$ & $\mathrm{Ni}$ & $\mathrm{V}$ & $\mathrm{Zn}$ & $\mathrm{Mn}$ & $\mathrm{Al}$ & $\mathrm{Fe}$ & $\mathrm{K}$ & $\mathrm{Ti}$ \\
\hline & $\mathrm{mg} / \mathrm{kg}$ & $\mathrm{mg} / \mathrm{kg}$ & $\mathrm{mg} / \mathrm{kg}$ & $\mathrm{mg} / \mathrm{kg}$ & $\mathrm{mg} / \mathrm{kg}$ & $\mathrm{mg} / \mathrm{kg}$ & $\mathrm{mg} / \mathrm{kg}$ & $\mathrm{mg} / \mathrm{kg}$ & $\mathrm{mg} / \mathrm{kg}$ & $\mathrm{mg} / \mathrm{kg}$ & $\mathrm{mg} / \mathrm{kg}$ & $\mathrm{mg} / \mathrm{kg}$ & $\mathrm{mg} / \mathrm{kg}$ \\
\hline P1-SF & 25 & 97 & 17 & 52 & 31 & 37 & 34 & 55 & 2.380 & 7.456 & 91.013 & 114 & 525 \\
\hline P1-BP & 44 & 163 & 22 & 69 & 48 & 57 & 44 & 69 & 3.491 & 7.310 & 99.677 & 184 & 669 \\
\hline P1-BL & 33 & 156 & 21 & 68 & 37 & 46 & 43 & 55 & 3.109 & 7.574 & 109.240 & 170 & 688 \\
\hline P1-BA-Sh-0-21 cm & 16 & 66 & 14 & 77 & 27 & 33 & 53 & 38 & 1.081 & 6.350 & 114.827 & 193 & 1.455 \\
\hline P1-BA- Sh-21-39 cm & 13 & 81 & 13 & 60 & 28 & 32 & 37 & 45 & 1.837 & 3.428 & 92.513 & 157 & 759 \\
\hline P1-BA-Sh-39-66 cm & 16 & 77 & 16 & 83 & 27 & 35 & 57 & 39 & 1.569 & 3.230 & 129.960 & 134 & 1.582 \\
\hline P1-BA-Sfm-66-76 cm & 23 & 130 & 19 & 70 & 37 & 49 & 46 & 55 & 2.244 & 4.420 & 97.085 & 120 & 1.086 \\
\hline P1-TA-Sr-0-23 cm & 12 & 76 & 18 & 102 & 31 & 48 & 64 & 47 & 1.717 & 6.923 & 103.758 & 221 & 1.624 \\
\hline P1-TA-Sm-23-42 cm & 10 & 62 & 18 & 96 & 26 & 45 & 59 & 47 & 1.556 & 6.915 & 98.388 & 250 & 1.429 \\
\hline P1-TA-Sm-42-60 cm & 12 & 74 & 19 & 108 & 31 & 50 & 67 & 57 & 1.751 & 8.712 & 107.548 & 286 & 1.629 \\
\hline P1-TA-Sm-60-72 cm & 13 & 80 & 21 & 118 & 34 & 53 & 75 & 61 & 1.821 & 10.217 & 120.456 & 352 & 2.006 \\
\hline P1-TA-Sfm-72-92 cm & 31 & 79 & 17 & 87 & 38 & 45 & 53 & 51 & 1.555 & 7.269 & 85.005 & 263 & 1.087 \\
\hline P1-TA-Sm-92-105 cm & 29 & 90 & 20 & 90 & 38 & 46 & 56 & 50 & 1.675 & 8.144 & 90.757 & 376 & 1.214 \\
\hline P1-TA-Sro-105-125 cm & 24 & 96 & 19 & 98 & 37 & 45 & 64 & 49 & 1.617 & 8.416 & 110.878 & 397 & 1.697 \\
\hline P2-SF & 41 & 211 & 36 & 90 & 54 & 66 & 59 & 83 & 4.943 & 11.179 & 127.979 & 266 & 1.068 \\
\hline P2-BP & 27 & 149 & 23 & 70 & 39 & 47 & 41 & 53 & 2.766 & 4.880 & 108.179 & 132 & 574 \\
\hline P2-BL & 33 & 143 & 21 & 75 & 41 & 50 & 48 & 62 & 2.864 & 7.750 & 104.782 & 198 & 1.319 \\
\hline P2-BB-Gcm-0-24 cm & 10 & 220 & 65 & 118 & 36 & 81 & 83 & 49 & 5.866 & 9.906 & 144.198 & 316 & 2.350 \\
\hline P2-BB-Sh-24-35 cm & 9 & 96 & 42 & 128 & 37 & 69 & 92 & 50 & 4.474 & 6.365 & 166.472 & 260 & 2.722 \\
\hline P2-BB-Sr-35-45 cm & 12 & 51 & 20 & 130 & 28 & 49 & 88 & 39 & 1.940 & 8.394 & 149.909 & 225 & 2.631 \\
\hline P2-BB-Sh-45-53 cm & 9 & 94 & 33 & 95 & 24 & 42 & 71 & 35 & 2.467 & 4.411 & 131.271 & 183 & 2.196 \\
\hline P2-TB-Col-0-22 cm & $<\mathrm{LQ}$ & 64 & 3 & 9 & 8 & 11 & 25 & 21 & 324 & 51.153 & 18.644 & 354 & 351 \\
\hline P2-TB-Sm+Col-22-60 cm & 10 & 35 & 16 & 76 & 30 & 42 & 52 & 49 & 1.616 & 6.995 & 85.706 & 195 & 1.239 \\
\hline P2-TB-Col-60-75 cm & $<\mathrm{LQ}$ & 64 & 8 & 32 & 15 & 24 & 34 & 33 & 899 & 32.931 & 38.465 & 456 & 610 \\
\hline P2-TB-Sh-75-92 cm & $<\mathrm{LQ}$ & 42 & 16 & 94 & 23 & 38 & 68 & 39 & 1.468 & 8.468 & 113.371 & 404 & 2.072 \\
\hline P2-TB-Sm+Col-92-122 cm & 8 & 56 & 16 & 76 & 27 & 40 & 57 & 42 & 1.613 & 18.520 & 84.710 & 480 & 1.325 \\
\hline P2-TB-Sfm-122-169 cm & 23 & 58 & 16 & 73 & 34 & 41 & 45 & 57 & 1.496 & 7.833 & 69.378 & 278 & 694 \\
\hline P2-TB-Sfm-169-192 cm & 27 & 49 & 16 & 68 & 33 & 37 & 40 & 45 & 1.206 & 5.889 & 65.498 & 239 & 629 \\
\hline LQ & 7,6 & 0,5 & 1,6 & 1,1 & 1,2 & 3,0 & 0,6 & 0,3 & 5,6 & 24,5 & 7,2 & 12,2 & 10,8 \\
\hline
\end{tabular}

P: ponto de coleta; B: barranco em que a amostra foi retirada; T: terraço em que a amostra foi retirada; SF: sedimento do fundo do canal; BP: barra em pontal; BL: barra longitudinal. Fácies associadas: Col: colúvio, Gcm: cascalho maciço suportado pelos clastos, Sfm: areia argilosa maciça, Sh: areia com laminação plano-paralela, Sm: areia maciça, Sr: areia com ripples ou laminação cruzada, Sro: areia com raízes. LQ: limite de quantificação.

tendência em se acumularem nos depósitos de canal, onde ocorrem sedimentos de maior granulometria.

Vale ressaltar que óxidos/hidróxidos de Fe e Mn atuam com mecanismos de sorção de elementos traço, o que explica as associações observadas entre os mesmos nos diversos depósitos estudados.

\section{Determinação dos valores de background}

Para a determinação dos valores de background, optou-se pela representação gráfica do tipo boxplot por possibilitar a separação de subconjuntos, sobretudo a separação de valores extremos associados às anomalias, facilitando assim a identificação de processos geoquímicos vinculados à distribuição dos dados (Reimann et al., 2005). Nesse sentido, a partir dos gráficos boxplot produzidos neste estudo (Figuras 11 e 12) foi possível visualizar as concentrações dos elementos investigados nas amostras e os dados suficientes para a realização dos cálculos e o estabelecimento dos valores de background (Tabela 6).

A partir da elaboração dos gráficos de boxplot associada à técnica TIF, foi possível distinguir concentrações naturais das anomalias dos elementos químicos estudados. De acordo com essa representação gráfica, os pontos situados fora da "caixa" são denominados outliers e indicam anomalias causadas por concentrações muito altas (pontos superiores à "caixa") e muito baixas (pontos inferiores à "caixa") dos elementos. Neste estudo, preocupou-se apenas com as anomalias relativas às altas concentrações identificadas nos terraços, barrancos e depósitos atuais. As principais anomalias identificadas nos terraços estão relacionadas aos teores elevados de $\mathrm{Al}, \mathrm{Cu}, \mathrm{Zn}$, Ni e $\mathrm{Cr}$ (em fácies arenosas e/ou cascalhosas de TD). Nos barrancos, as anomalias estão relacionadas às 
Santos, R. L. e Costa, A. T.

Tabela 4. Resultados químicos das amostras coletadas nos pontos 03 a 06.

\begin{tabular}{|c|c|c|c|c|c|c|c|c|c|c|c|c|c|}
\hline \multirow{2}{*}{ Amostra } & As & $\mathrm{Ba}$ & Co & $\mathrm{Cr}$ & $\mathrm{Cu}$ & $\mathrm{Ni}$ & V & $\mathrm{Zn}$ & $\mathrm{Mn}$ & Al & $\mathrm{Fe}$ & $\mathrm{K}$ & $\mathrm{Ti}$ \\
\hline & $\mathrm{mg} / \mathrm{kg}$ & $\mathrm{mg} / \mathrm{kg}$ & $\mathrm{mg} / \mathrm{kg}$ & $\mathrm{mg} / \mathrm{kg}$ & $\mathrm{mg} / \mathrm{kg}$ & $\mathrm{mg} / \mathrm{kg}$ & $\mathrm{mg} / \mathrm{kg}$ & $\mathrm{mg} / \mathrm{kg}$ & $\mathrm{mg} / \mathrm{kg}$ & $\mathrm{mg} / \mathrm{kg}$ & $\mathrm{mg} / \mathrm{kg}$ & $\mathrm{mg} / \mathrm{kg}$ & $\mathrm{mg} / \mathrm{kg}$ \\
\hline P3-SF & 34 & 182 & 31 & 86 & 46 & 63 & 56 & 63 & 4.198 & 6.539 & 127.288 & 172 & 1.145 \\
\hline P3-BP & 21 & 148 & 20 & 85 & 34 & 46 & 57 & 46 & 3.021 & 4.991 & 131.435 & 154 & 1.604 \\
\hline P3-TC-Gmm-0 -18 cm & $<\mathrm{LQ}$ & 54 & 21 & 110 & 29 & 47 & 81 & 37 & 2.002 & 6.885 & 137.041 & 195 & 2.444 \\
\hline P3-TC-Sm-18 - 83 cm & 9 & 53 & 20 & 121 & 30 & 49 & 88 & 40 & 1.904 & 9.358 & 143.322 & 322 & 2.570 \\
\hline P3-TC-Sh-83-133 cm & 9 & 45 & 16 & 81 & 27 & 43 & 55 & 33 & 1.890 & 4.728 & 95.529 & 130 & 1.463 \\
\hline P3-TC-Sm-133-176 cm & 12 & 57 & 20 & 87 & 32 & 51 & 58 & 41 & 1.991 & 7.555 & 91.920 & 182 & 1.206 \\
\hline P4-SF & 48 & 337 & 28 & 66 & 46 & 47 & 44 & 66 & 6.577 & 8.535 & 119.509 & 208 & 388 \\
\hline P4-BP & 46 & 228 & 25 & 70 & 47 & 48 & 43 & 59 & 3.382 & 6.244 & 103.228 & 197 & 408 \\
\hline P4-BL & 9 & 69 & 23 & 89 & 35 & 47 & 66 & 47 & 2.291 & 3.754 & 115.926 & 185 & 1.520 \\
\hline P4-BC-Gcm-0-27 cm & 42 & 256 & 35 & 70 & 53 & 55 & 43 & 65 & 3.465 & 5.759 & 99.375 & 197 & 348 \\
\hline P4-BC-Sh+Sr-27-49 cm & 34 & 131 & 13 & 43 & 33 & 32 & 28 & 46 & 2.034 & 2.805 & 89.293 & 151 & 440 \\
\hline P4-BC-Sh-49-72 cm & 44 & 167 & 16 & 51 & 38 & 40 & 33 & 57 & 2.650 & 4.414 & 90.735 & 146 & 354 \\
\hline P5-BL/BP & 25 & 136 & 15 & 52 & 32 & 35 & 32 & 41 & 2.077 & 3.641 & 89.434 & 129 & 542 \\
\hline P5-BD-Gmm-0-70 cm & 12 & 64 & 33 & 117 & 45 & 65 & 89 & 53 & 3.220 & 19.922 & 117.273 & 549 & 1.560 \\
\hline P5-BD-Sm-70-130 cm & $<\mathrm{LQ}$ & 52 & 29 & 106 & 33 & 46 & 88 & 38 & 2.927 & 19.231 & 125036 & 461 & 1.773 \\
\hline P5-BD-Fm-130-140 cm & 8 & 22 & 18 & 83 & 37 & 29 & 65 & 46 & 509 & 19.638 & 91.572 & 269 & 888 \\
\hline P5-BD-Fm-140-200 cm & $<\mathrm{LQ}$ & 34 & 10 & 170 & 31 & 27 & 118 & 38 & 577 & 72.223 & 110.268 & 970 & 1.200 \\
\hline P6-SF & 49 & 181 & 23 & 73 & 48 & 52 & 47 & 86 & 2.976 & 8.604 & 86.064 & 262 & 551 \\
\hline P6-TD-Gmm-0-120 cm & 18 & 54 & 22 & 175 & 128 & 109 & 99 & 101 & 295 & 15.843 & 128.107 & 356 & 1.016 \\
\hline P6-TD-Sm-120-165 cm & $<\mathrm{LQ}$ & 37 & 11 & 161 & 53 & 55 & 96 & 52 & 141 & 13.350 & 60.670 & 331 & 1.131 \\
\hline P6-TD-Sm-165-230 cm & $<\mathrm{LQ}$ & 48 & 12 & 132 & 52 & 53 & 87 & 49 & 152 & 15.353 & 41.139 & 515 & 1.104 \\
\hline P6-TD-Sm-230-310 cm & $<\mathrm{LQ}$ & 29 & 18 & 208 & 106 & 87 & 119 & 45 & 186 & 12.962 & 82.409 & 313 & 1.407 \\
\hline P6-TD-Sm-310-405 cm & $<\mathrm{LQ}$ & 19 & 4 & 113 & 26 & 20 & 74 & 17 & 35 & 9.905 & 13.164 & 185 & 1.025 \\
\hline P6-TD-Sh-405-415 cm & $<\mathrm{LQ}$ & 5 & $<\mathrm{LQ}$ & 19 & 6 & 5 & 15 & 7 & 7 & 2.421 & 2.285 & 128 & 340 \\
\hline P6-TD-C-415-495 cm & $<\mathrm{LQ}$ & 42 & 2 & 94 & 18 & 10 & 90 & 10 & 31 & 19.906 & 14.696 & 537 & 501 \\
\hline P6-TD-Fsm-495-585 cm & $<\mathrm{LQ}$ & 49 & 4 & 129 & 34 & 26 & 103 & 14 & 71 & 23.386 & 29.681 & 519 & 1.103 \\
\hline$L Q$ & 7,6 & 0,5 & 1,6 & 1,1 & 1,2 & 3,0 & 0,6 & 0,3 & 5,6 & 24,5 & 7,2 & 12,2 & 10,8 \\
\hline
\end{tabular}

P: ponto de coleta; B: barranco em que a amostra foi retirada; T: terraço em que a amostra foi retirada; SF: sedimento do fundo do canal; BP: barra em pontal; BL: barra longitudinal. Fácies associadas: Gcm: cascalho maciço suportado pelos clastos, Sfm: areia argilosa maciça, Sh: areia com laminação plano-paralela, Sm: areia maciça, Sr: areia com ripples ou laminação cruzada, Sro: areia com raízes. LQ: limite de quantificação.

altas concentrações de $\mathrm{Al}$ (fácies de planície de inundação de $\mathrm{BD}$ ) e Co (nas fácies cascalhosas de BB, BC e BD) e nos sedimentos atuais aos teores elevados de Co e $\mathrm{Zn}$, no ponto 02, de Ba e Mn, no ponto 04, e de Zn no ponto 06. Portanto, foi possível observar três padrões de anomalias geoquímicas. O primeiro, que engloba os elementos $\mathrm{Cu}, \mathrm{Ni}$ e $\mathrm{Cr}$, é resultante de fontes geogênicas, já que os valores anômalos desses elementos ocorreram apenas nos terraços. O segundo, constituído por $\mathrm{Co}$, $\mathrm{Mn}$ e $\mathrm{Ba}$, resulta de fontes antropogênicas, já que está relacionado aos sedimentos mais recentes (barrancos e atuais). O terceiro é composto por $\mathrm{Al}$ e Zn, elementos que podem ser provenientes de fontes geogênicas ou antropogênicas, por estarem presentes tanto nos terraços quanto nos depósitos mais recentes. Vale ressaltar que a anomalia causada por Ni na fácies de canal do barranco BB foi interpretada como uma interferência dos depósitos de canal do terraço $\mathrm{TB}$, já que os outros barrancos não apresentaram anomalia referente a esse elemento. Considerando o contexto geológico da área de estudo, as altas concentrações de $\mathrm{Al}$ estão relacionadas às rochas do embasamento do Complexo Bação; e os teores elevados de $\mathrm{Cu}$ e $\mathrm{Zn}$, às supracrustais dos supergrupos Rio das Velhas e Minas, sequências ricas em 
metais e elementos traço. As altas concentrações de Ni, Co e $\mathrm{Cr}$ provavelmente estão associadas às intrusões ultramáficas ocorridas na região.

\section{DISCUSSÃO}

Trabalhos como os de Cole (1998), Hudson-Edwards et al. (1998) e Gleyzes et al. (2002) encontraram concentrações elevadas de elementos traço em fácies de sedimentos finos de planícies de inundação e lagoas de cheia, associados a argilominerais e matéria orgânica. Neste estudo, através das PCA, foi possível observar concentrações elevadas desses elementos em fácies predominantemente cascalhosas, de canal, e arenosas, de barras, corroborando o estudo de Costa (2007). Elementos traço como As, Ba e Zn, Co, Ni, Cu, Ti e $\mathrm{Cr}$ indicaram forte associação com óxidos/hidróxidos de $\mathrm{Mn}$ e Fe, respectivamente.

Os valores de background geoquímico calculados neste trabalho foram comparados com valores de background obtidos a partir da mesma técnica em estudos anteriores realizados no Quadrilátero Ferrífero (Tabela 7). Dessa forma, notou-se que a maior parte dos valores encontrados neste estudo é menor do que aqueles apresentados por Vicq (2015), com exceção do $\mathrm{Ba}$, não considerado pelo autor, e do As. No caso desse último elemento, o background encontrado foi quase três vezes o valor de referência obtido por Vicq (2015). Considerando que o autor mencionado analisou geoquimicamente um total de 541 amostras de sedimentos fluviais em todo o Quadrilátero Ferrífero, provavelmente as diferenças entre os valores de background sejam devidas à maior diversidade e especificidade dos litotipos amostrados (Vicq et al., 2015). Comparando-se os valores encontrados com aqueles estabelecidos por Rodrigues (2012) e Rodrigues et al. (2014), nota-se que os valores de background para o Fe, Zn e Ni são semelhantes, provavelmente devido à semelhança da distribuição espacial das unidades aflorantes nas áreas de estudo, que no caso desses trabalhos supracitados, envolveram aproximadamente 50\% de rochas do embasamento e rochas dos supergrupos Rio das Velhas e Minas. Entretanto, como o trabalho de Vicq (2015) englobou amostras de todo o Quadrilátero Ferrífero, pode-se dizer que trata-se de um estudo mais representativo para abalizar levantamentos de background realizados nessa província mineral.

Considerando os valores orientadores de qualidade dos solos estabelecidos no estado de São Paulo e na Holanda (CETESB, 2001), as concentrações máximas de As encontradas na área de estudo foram maiores que o limite de intervenção agrícola na maior parte dos pontos; e as de Ni foram maiores em todos os pontos. As concentrações máximas de Ba encontram-se acima do limite de alerta na maior parte dos pontos. Em todos os locais de amostragem foram observadas concentrações de $\mathrm{Cr}$ acima do limite de alerta. Tendo em vista o grau de contaminação causado pelos elementos citados, toda a área da bacia requer intervenção agrícola devido às altas concentrações de As e $\mathrm{Ni}$ e monitoramento com relação aos teores de $\mathrm{Ba}$ e $\mathrm{Cr}$.

Com relação a alguns critérios existentes para avaliação da qualidade dos sedimentos fluviais, observou-se que o limite superior do background para o As se encontra muito próximo ao nível de provável efeito adverso segundo o Ontario Ministry of the Environment and Energy (OMEE, 1993), MacDonald et al. (2000), Basílio (2005) e o Canadian Council of Ministers of the Environment (CCME, 2003). Quanto ao background para o $\mathrm{Cr}$, o limite superior está acima dos níveis de provável efeito adverso, de acordo com os critérios mencionados e com o valor proposto por Smith et al. (1996). O background para o Ni está acima do limite de provável efeito adverso, considerando a maior parte dos critérios supracitados, exceto a OMEE (1993). Os valores de background para o Fe e o Mn estão muito acima dos níveis

Tabela 5. Principais correlações de Pearson observadas.

\begin{tabular}{|c|c|c|}
\hline $\begin{array}{l}\text { Amostras } \\
\text { incluídas }\end{array}$ & $\begin{array}{c}\text { Principais } \\
\text { correlações } \\
\text { obtidas }\end{array}$ & $\begin{array}{l}\text { Coeficientes de } \\
\text { correlação de Pearson }\end{array}$ \\
\hline \multirow{7}{*}{ Todas } & As versus $\mathrm{Ba}$ & 0,813 \\
\hline & Ba versus Mn & 0,837 \\
\hline & Co versus Mn & 0,813 \\
\hline & Co versus Fe & 0,731 \\
\hline & Cr versus V & 0,945 \\
\hline & Cu versus Ni & 0,816 \\
\hline & Al versus K & 0,805 \\
\hline \multirow{5}{*}{ Terraços } & Co versus Mn & 0,751 \\
\hline & Co versus Fe & 0,935 \\
\hline & Cr versus V & 0,937 \\
\hline & Cu versus $\mathrm{Ni}$ & 0,902 \\
\hline & Fe versus Ti & 0,827 \\
\hline \multirow{7}{*}{ Barrancos } & As versus Zn & 0,701 \\
\hline & Co versus Mn & 0,915 \\
\hline & Cr versus V & 0,981 \\
\hline & Cu versus Zn & 0,892 \\
\hline & Ni versus Mn & 0,931 \\
\hline & Al versus K & 0,952 \\
\hline & Fe versus Ti & 0,954 \\
\hline \multirow{9}{*}{$\begin{array}{l}\text { Depósitos } \\
\text { atuais }\end{array}$} & As versus $\mathrm{Ba}$ & 0,781 \\
\hline & As versus $\mathrm{Cu}$ & 0,798 \\
\hline & As versus Zn & 0,781 \\
\hline & As versus Al & 0,708 \\
\hline & Ba versus Mn & 0,895 \\
\hline & Co versus Mn & 0,753 \\
\hline & Crversus V & 0,967 \\
\hline & Cu versus Ni & 0,859 \\
\hline & Cu versus Zn & 0,868 \\
\hline
\end{tabular}



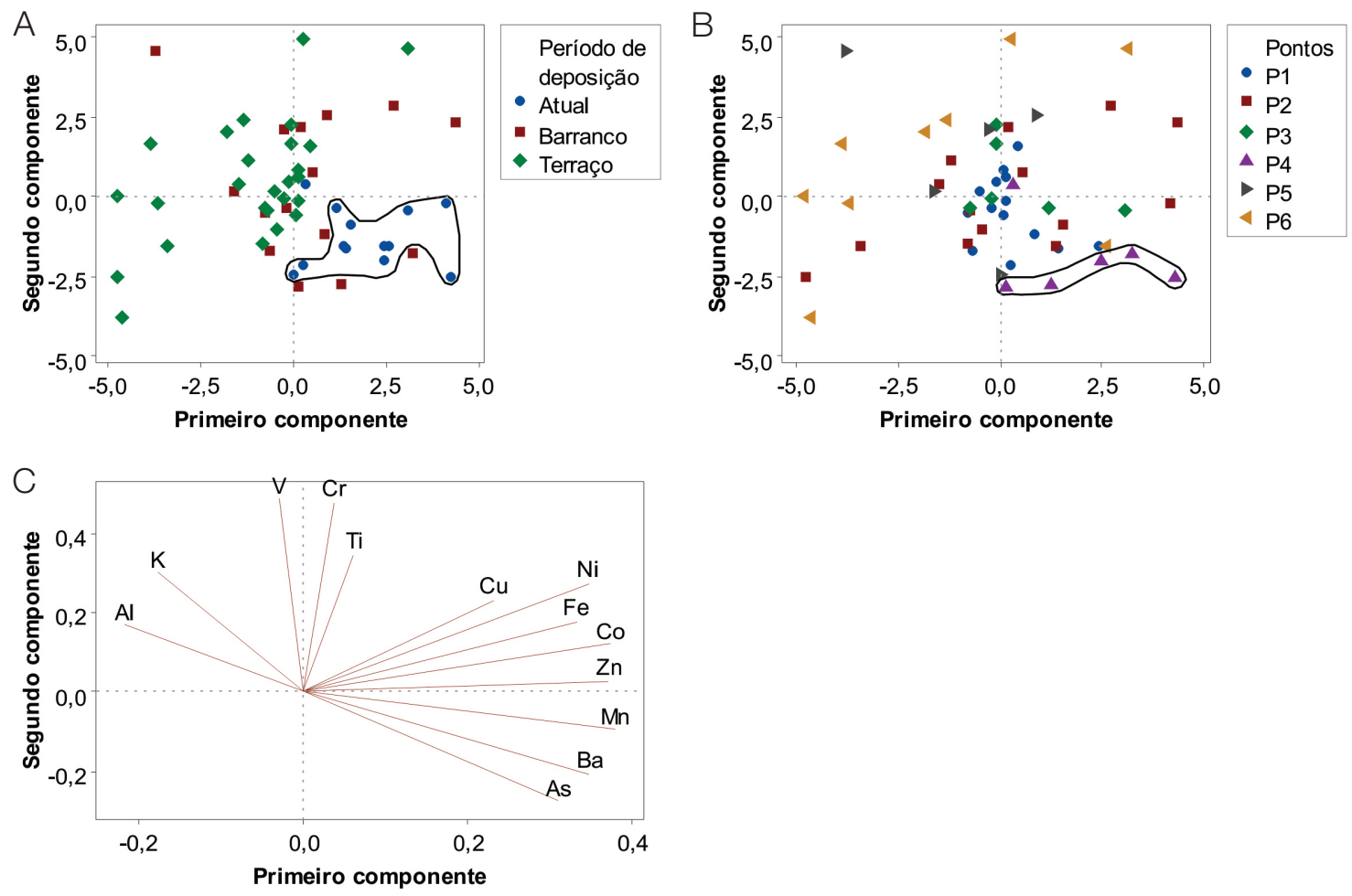

Figura 9. Análise de componentes principais. (A) Gráficos de espalhamento considerando o período de deposição e (B) os pontos de amostragem; (C) gráfico de pesos.
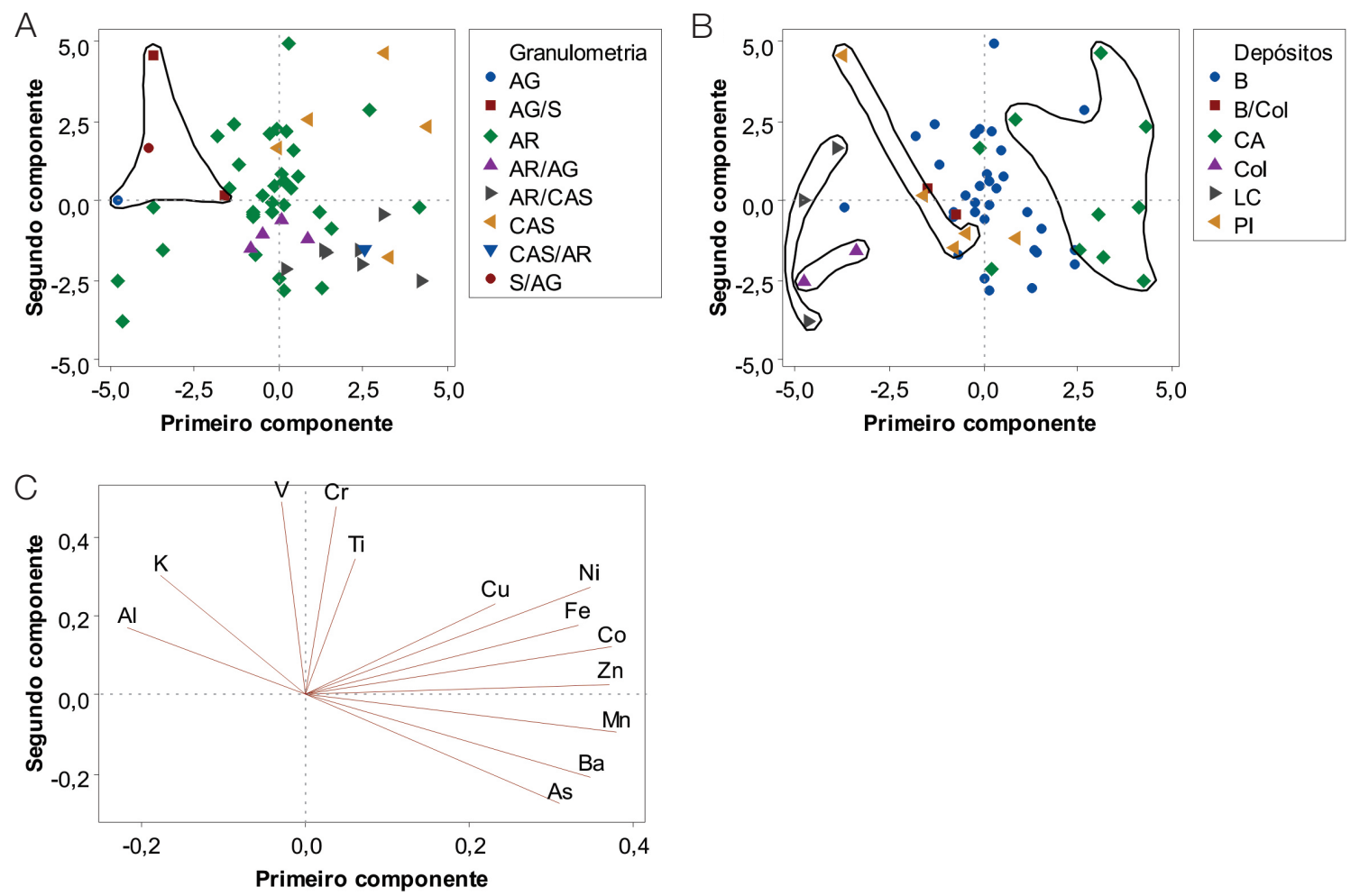

AG: argila, S: silte, AR: areia, CAS: cascalho. Tipo de depósitos: B: barras, Col: colúvio, CA: canal, LC: lagoa de cheia, PI: planície de inundação.

Figura 10. Análise de componentes principais. (A) Gráficos de espalhamento considerando a granulometria dos depósitos e (B) os tipos de depósitos; (C) gráfico de pesos. 
de provável efeito severo de acordo com a OMEE (1993), os demais órgãos não apresentaram limites de concentração para esses elementos.

De acordo com os critérios de avaliação da qualidade dos sedimentos utilizados e os valores de background calculados neste estudo, notou-se que as concentrações naturais dos elementos $\mathrm{As}, \mathrm{Cr}, \mathrm{Ni}, \mathrm{Fe}$ e $\mathrm{Mn}$ podem ser consideradas elevadas. Valores altos de background também foram encontrados para os elementos $\mathrm{Zn}(66,6 \mathrm{mg} /$ $\mathrm{kg})$ e $\mathrm{Pb}(57,8 \mathrm{mg} / \mathrm{kg})$, de acordo com Sakan et al. (2015), em um estudo realizado mais recentemente na Sérvia, na Bacia do Rio Danúbio, onde ocorrem depósitos de $\mathrm{Pb}, \mathrm{Zn}$ e $\mathrm{Cu}$. Garcia-Ordiales et al. (2017) também mostraram concentrações elevadas de background para o Zn (79,7
A

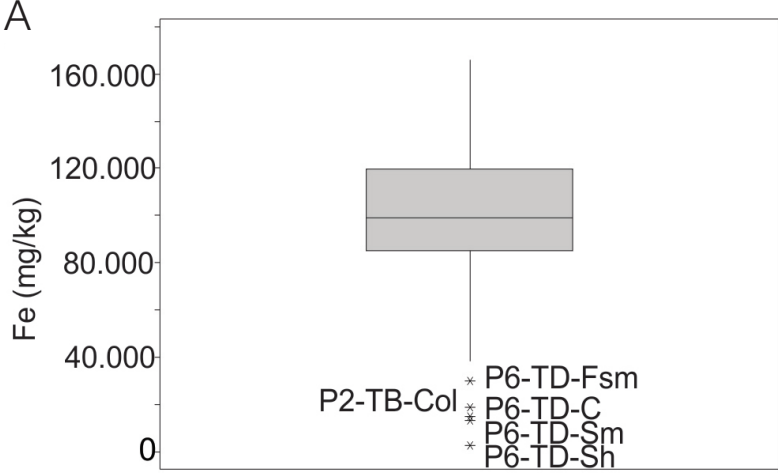

C

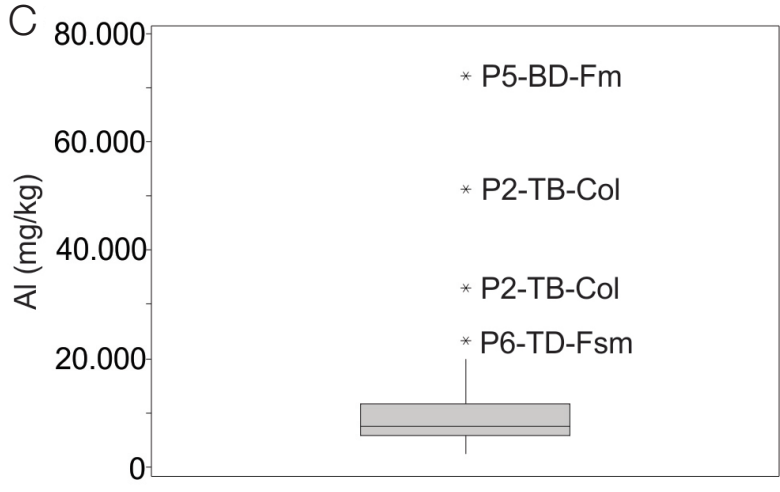

E.

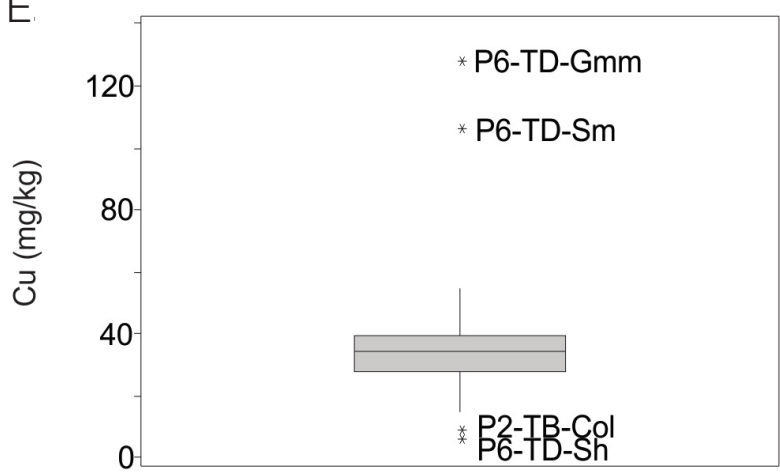

B

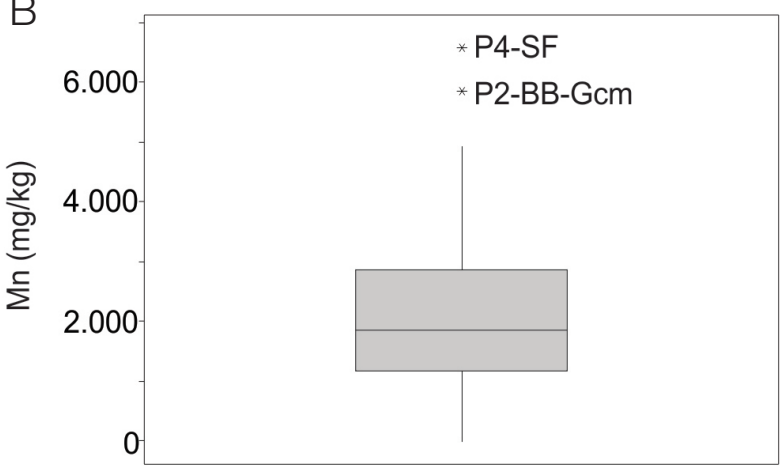

$\mathrm{D}$

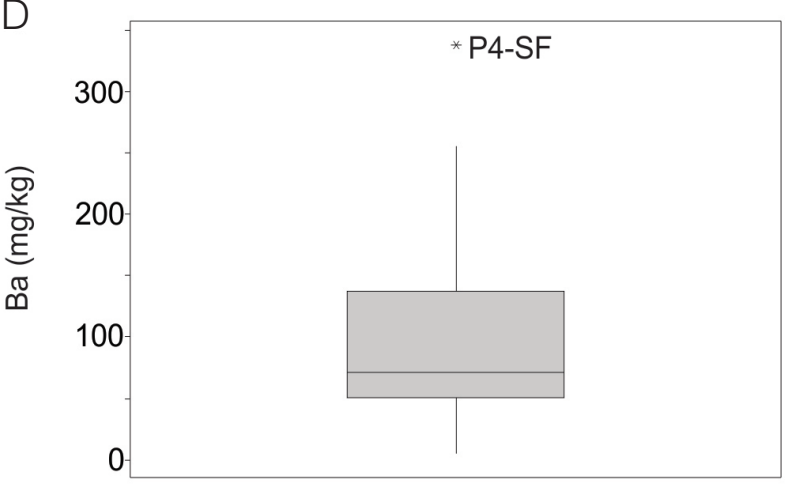

$\mathrm{F}$

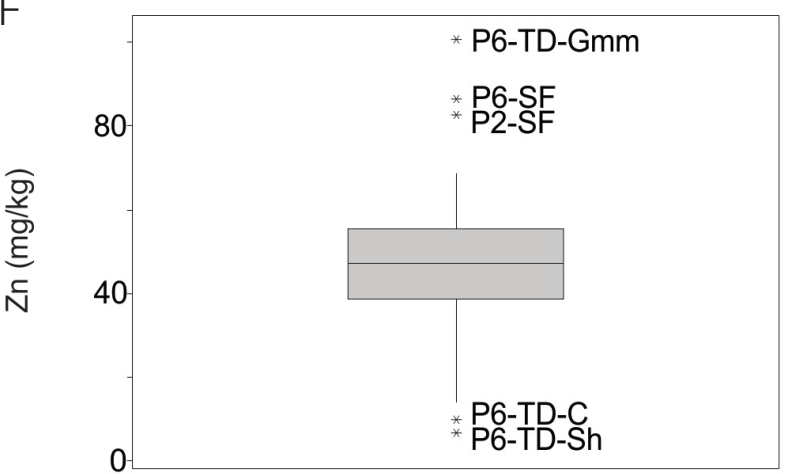

P: ponto de coleta; B: barranco em que a amostra foi retirada; T: terraço em que a amostra foi retirada. SF: sedimento do fundo do canal. Fácies associadas: C: argila carbonosa, Col: colúvio, Fm: argila siltosa maciça, Fsm: silte argiloso maciço, Gcm: cascalho maciço suportado pelos clastos, Gmm: cascalho maciço suportado pela matriz, Sh: areia com laminação plano-paralela, Sm: areia maciça.

Figura 11. Representação boxplot das concentrações dos elementos (A) Fe, (B) Mn, (C) Al, (D) Ba, (E) Cu e (F) Zn enfatizando as concentrações anômalas. 
$\mathrm{mg} / \mathrm{kg})$ e $\mathrm{Pb}(25,8 \mathrm{mg} / \mathrm{kg})$ na região de Almadén, porção centro-sul da Espanha, onde ocorrem depósitos polimetálicos de $\mathrm{Pb}-\mathrm{Zn}$. Vale ressaltar que o valor do background para o As, calculado neste estudo, e os demais valores relacionados aos trabalhos supracitados encontram-se acima da concentração média da crosta continental $(2 \mathrm{mg} / \mathrm{kg})$ (Reimann e Caritat, 1998; Vicq, 2015). Contudo, esses resultados mostram que mesmo sem influência antrópica, o ambiente superficial pode ser enriquecido em elementos que são de grande ocorrência em uma dada região.
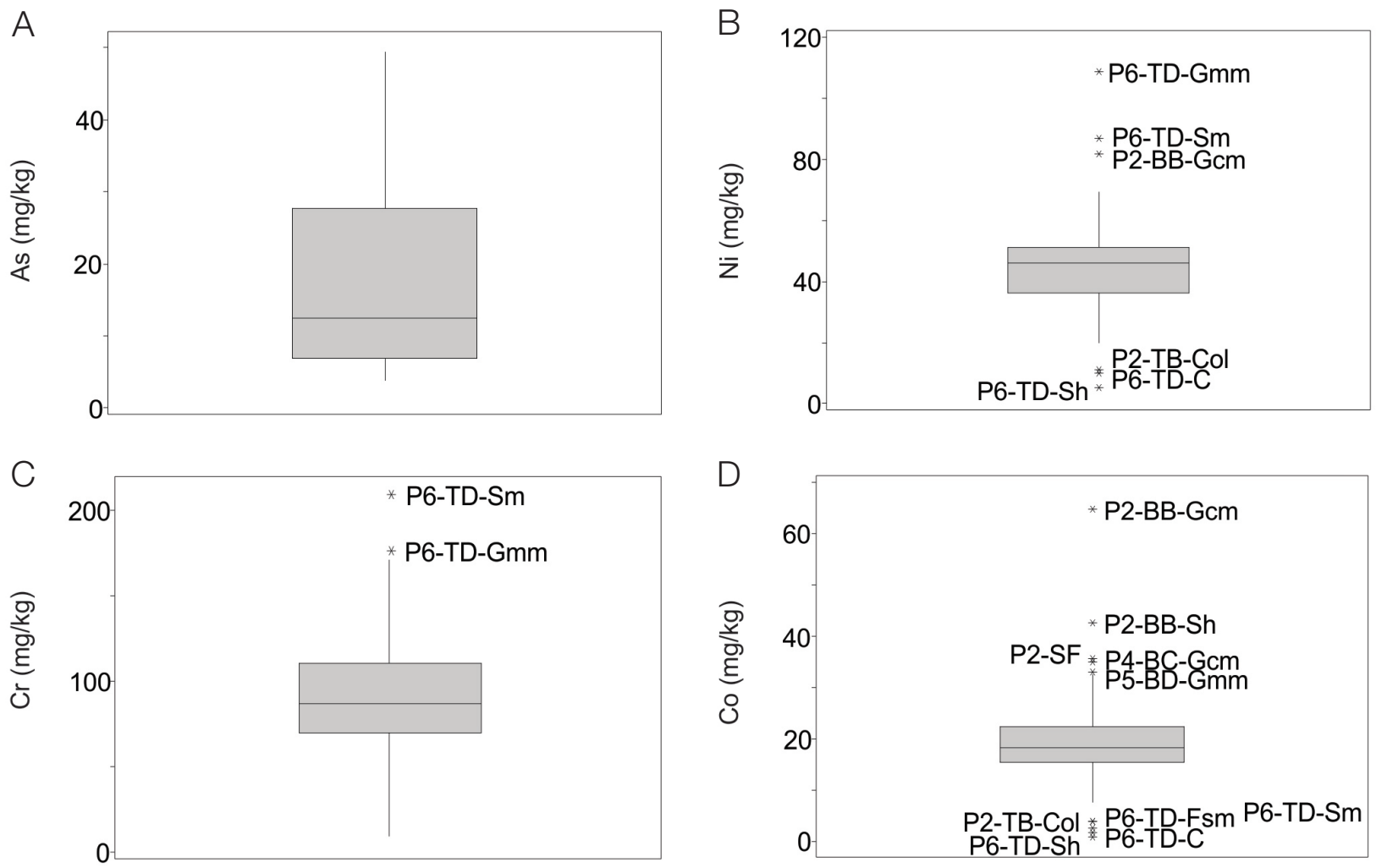

P: ponto de coleta; B: barranco em que a amostra foi retirada; T: terraço em que a amostra foi retirada. SF: sedimento do fundo do canal. Fácies associadas: C: argila carbonosa, Col: colúvio, Fsm: silte argiloso maciço, Gcm: cascalho maciço suportado pelos clastos, Gmm: cascalho maciço suportado pela matriz, Sh: areia com laminação plano-paralela, Sm: areia maciça.

Figura 12. Representação boxplot das concentrações dos elementos (A) As, (B) $\mathrm{Ni}$, (C) $\mathrm{Cr}$ e (D) Co enfatizando as concentrações anômalas.

Tabela 6. Cálculo dos valores de background pelo método estatístico.

\begin{tabular}{|c|c|c|c|c|c|c|c|}
\hline $\begin{array}{l}\text { Elementos } \\
(\mathrm{mg} / \mathrm{kg})\end{array}$ & Q1 & Mediana & Q3 & $\mathrm{IQ}$ & $\begin{array}{c}{[Q 1-1 / 2 x} \\
(1,5 \mathrm{IQ}-\mathrm{IQ})]\end{array}$ & $\begin{array}{c}{[Q 3+1 / 2 x} \\
(1,5 I Q-I Q)]\end{array}$ & Background \\
\hline $\mathrm{Fe}$ & $85.530,70$ & $99.526,00$ & $119.746,00$ & $34.215,00$ & $76.976,95$ & $128.299,75$ & $11,01-18,34^{*}$ \\
\hline $\mathrm{Mn}$ & $1.174,94$ & $1.863,42$ & $2.880,16$ & $1.705,22$ & 748,64 & $3.306,47$ & $748,64-3.306,47$ \\
\hline $\mathrm{Al}$ & $5.856,69$ & $7.661,53$ & $11.624,80$ & $5.768,08$ & $4.414,67$ & $13.066,82$ & $0,83-2,47^{\star \star}$ \\
\hline $\mathrm{Ba}$ & 50,66 & 71,74 & 137,76 & 87,11 & 28,88 & 159,54 & $28,88-159,54$ \\
\hline $\mathrm{Cu}$ & 27,65 & 34,01 & 39,74 & 12,09 & 24,63 & 42,76 & $24,63-42,76$ \\
\hline Zn & 38,88 & 47,15 & 55,43 & 16,55 & 34,74 & 59,57 & $34,74-59,57$ \\
\hline As & 6,90 & 12,48 & 27,69 & 20,79 & 1,70 & 32,89 & 1,70-32,89 \\
\hline $\mathrm{Ni}$ & 36,29 & 46,00 & 51,22 & 14,93 & 32,56 & 54,95 & $32,56-54,95$ \\
\hline $\mathrm{Cr}$ & 69,54 & 86,34 & 110,52 & 40,98 & 59,30 & 120,77 & $59,30-120,77$ \\
\hline Co & 15,55 & 18,40 & 22,50 & 6,94 & 13,82 & 24,24 & $13,82-24,24$ \\
\hline
\end{tabular}

Q1: primeiro quartil; Q3: terceiro quartil; IQ: intervalo interquartil; *as concentrações de Fe foram convertidas em valores percentuais de Fe $\mathrm{O}_{3}$; ${ }^{*}$ as concentrações de Al foram convertidas em valores percentuais de $\mathrm{Al}_{2} \mathrm{O}_{3}$. 


\section{CONCLUSÃO}

Os perfis analisados são típicos de empilhamento sedimentar formado em ambiente fluvial meandrante. A ocorrência de sequências com granodecrescência ascendente (depósitos BA, TA, BD e TD) e sucessões formadas, da base para o topo, por cascalhos, areias e sedimentos finos (depósitos $\mathrm{BB}, \mathrm{TC}, \mathrm{BC}, \mathrm{BD}$ e TD), resulta da migração lateral do rio.

Os estudos faciológicos e mineralógicos indicaram o maior acúmulo de óxidos e hidróxidos de Fe nas fácies de canal e barras. Além disso, as PCA mostraram um padrão geoquímico formado por depósitos de canal associados às elevadas concentrações de $\mathrm{Mn}$ e Fe. Também foi observado um padrão geoquímico resultante dos altos teores de Mn nos depósitos atuais da bacia. Em ambos os padrões, o Fe e o Mn encontram-se associados a elementos traço, o que pode ser devido ao comportamento de óxidos/hidróxidos desses elementos que promovem mecanismos de sorção com elementos traço. Os itabiritos do Grupo Itabira são as principais fontes de $\mathrm{Fe}$ e Mn na região. As análises mineralógicas mostraram a presença de caulinita em quase todas as fácies, o que corrobora os dados geoquímicos, que indicaram a presença de $\mathrm{Al}$ nos principais depósitos estudados. As maiores concentrações desse elemento ocorreram nas fácies de planície de inundação e de lagoa de cheia, ambientes propícios à deposição de argilominerais em períodos de inundação, e em fácies que apresentaram material coluvionar, resultante do intemperismo

Tabela 7. Valores de background geoquímico para o Quadrilátero Ferrífero calculados via boxplot.

\begin{tabular}{|c|c|c|c|}
\hline Elementos & $\begin{array}{l}\text { Rodrigues } \\
(2012)^{\star}\end{array}$ & $\begin{array}{c}\text { Vicq } \\
(2015)^{\star \star}\end{array}$ & $\begin{array}{c}\text { Limite } \\
\text { superior } \\
\text { calculado } \\
\text { neste } \\
\text { trabalho }\end{array}$ \\
\hline $\mathrm{Fe}_{2} \mathrm{O}_{3}(\%)$ & 13,01 & 58,22 & 18,34 \\
\hline $\mathrm{Mn}(\mathrm{mg} / \mathrm{kg})$ & $\begin{array}{c}\text { não } \\
\text { estabelecido }\end{array}$ & $3.875,00$ & $3.306,47$ \\
\hline $\mathrm{Al}_{2} \mathrm{O}_{3}(\%)$ & $\begin{array}{c}\text { não } \\
\text { estabelecido }\end{array}$ & 9,60 & 2,47 \\
\hline $\mathrm{Ba}(\mathrm{mg} / \mathrm{kg})$ & $\begin{array}{c}\text { não } \\
\text { estabelecido }\end{array}$ & $\begin{array}{c}\text { não } \\
\text { estabelecido }\end{array}$ & 159,54 \\
\hline $\mathrm{Cu}(\mathrm{mg} / \mathrm{kg})$ & $\begin{array}{c}\text { não } \\
\text { estabelecido }\end{array}$ & 68,36 & 42,76 \\
\hline Zn (mg/kg) & 68,20 & 98,14 & 59,57 \\
\hline As $(\mathrm{mg} / \mathrm{kg})$ & $\begin{array}{c}\text { não } \\
\text { estabelecido }\end{array}$ & 12,75 & 32,89 \\
\hline $\mathrm{Ni}(\mathrm{mg} / \mathrm{kg})$ & 38,60 & 95,83 & 54,95 \\
\hline $\mathrm{Cr}(\mathrm{mg} / \mathrm{kg})$ & $\begin{array}{c}\text { não } \\
\text { estabelecido }\end{array}$ & 269,20 & 120,77 \\
\hline Co $(\mathrm{mg} / \mathrm{kg})$ & $\begin{array}{c}\text { não } \\
\text { estabelecido }\end{array}$ & 37,56 & 24,24 \\
\hline
\end{tabular}

*Estudo realizado na porção SE do Quadrilátero Ferrífero; **o autor considerou amostras coletadas em todo o Quadrilátero Ferrífero. de rochas granito-gnáissicas enriquecidas em alumino-silicatos. Essas rochas são as principais fontes de $\mathrm{Al}$ na região.

Comparando-se os valores de background obtidos neste estudo com aqueles encontrados no Quadrilátero Ferrífero através da mesma metodologia, pode-se dizer que os valores apresentados neste trabalho são coerentes com os demais, com exceção do As, que apresentou um limite superior de background quase três vezes maior que o apresentado por Vicq (2015).

A abundância de Fe e Mn na bacia de estudo também está refletida nos altos valores de background associados a esses elementos. A relação estreita entre os depósitos atuais do Ribeirão Sardinha e o Mn é provavelmente um indício de que a disponibilização desse elemento está sendo influenciada pela exploração do minério de $\mathrm{Fe}$, intensificada nos últimos anos. O Mn também mostrou uma forte relação com o As nas análises de PCA e isso pode estar refletindo nos seus respectivos níveis de background geoquímico.

Foram observados três padrões de anomalias geoquímicas. O primeiro, formado por $\mathrm{Cu}, \mathrm{Ni}$ e $\mathrm{Cr}$, resulta de fontes geogênicas, já o segundo, constituído por $\mathrm{Co}, \mathrm{Mn}$ e $\mathrm{Ba}$, apresenta valores anômalos provenientes de fontes antropogênicas. $\mathrm{O}$ terceiro padrão é formado por $\mathrm{Al}$ e $\mathrm{Zn}$, elementos provenientes tanto de fontes geogênicas quanto antropogênicas. As anomalias de $\mathrm{Al}$ nas fácies de planície de inundação (BD) e de lagoa de cheia (TD) estão relacionadas com a erosão de rochas do embasamento enriquecidas em alumino-silicatos, que geram sedimentos facilmente transportados como materiais em suspensão para as margens ou porções externas ao canal. As diversas anomalias observadas neste trabalho refletem a diversidade geológica da região de estudo.

Com relação aos valores orientadores de solos para o estado de São Paulo e Holanda, ocorreram concentrações maiores do que o limite de intervenção agrícola para o As na maior parte dos pontos e para o $\mathrm{Ni} \mathrm{em}$ todos os pontos de investigação. Também foram observadas concentrações acima do limite de alerta para o $\mathrm{Cr}$, em todos os pontos, e para o $\mathrm{Ba}$ em quase todos os locais de amostragem. Considerando os teores elevados de As e Ni na bacia do Ribeirão Sardinha, sobretudo no distrito de Engenheiro Correia, onde a comunidade comumente realiza práticas agrícolas, aconselha-se a suspensão do cultivo e da criação de animais para abate em toda a área de estudo devido ao risco toxicológico associado a esses elementos via cadeia alimentar. Considerando os valores obtidos de $\mathrm{Ba}$ e $\mathrm{Cr}$, toda a bacia requer monitoramento das concentrações desses elementos.

Com relação aos valores-guia de qualidade dos sedimentos, os valores de background encontrados para os elementos As, $\mathrm{Cr}, \mathrm{Ni}, \mathrm{Mn}$ e Fe podem ser considerados críticos, uma vez que o As encontra-se próximo ao limite de provável efeito adverso à biota e os demais elementos encontram-se acima desse nível. 
Contudo, ressalta-se a relevância deste estudo por ter proporcionado melhor compreensão das características geoquímicas dos sedimentos dispostos na Bacia do Ribeirão Sardinha e revelado os riscos ambientais associados principalmente aos elementos traço (As, $\mathrm{Ni}, \mathrm{Ba}$ e $\mathrm{Cr}$ ) em uma área propícia à contaminação devido às práticas históricas e atuais de exploração mineral. Acredita-se que os valores de background obtidos poderão ser úteis em outros estudos e até mesmo contribuir para a formação de um futuro banco de dados mais completo, que pode vir a ser realizado através de parcerias entre órgãos de pesquisa e participação governamental. Os dados também poderão ser utilizados para a delimitação de possíveis áreas de intervenção orientadas por autoridades ambientais.

\section{AGRADECIMENTOS}

As autoras agradecem imensamente o suporte financeiro da Fundação de Amparo à Pesquisa de Minas Gerais (FAPEMIG), via projeto CRA PPM 00232-13, e da Fundação Gorceix, que contribuiu para a realização das análises de datação. Nossos sinceros agradecimentos às equipes dos laboratórios de geoquímica e de difração de raios X do Departamento de Geologia da Universidade Federal de Ouro Preto (UFOP) pelo comprometimento na entrega dos resultados.

\section{REFERÊNCIAS}

Alkmim, F. F., Marshak, S. (1998). Transamazonian Orogeny in the Southern São Francisco Craton, Minas Gerais, Brazil: Evidence for Paleoproterozoic collision and collapse in the Quadrilátero Ferrífero. Precambrian Research, 90, 29-58. https://doi.org/S0301-9268(98)00032-1

Basílio, M. S. (2005). Geoquímica dos sedimentos associados aos minérios de ferro da região leste - sudeste do Quadrilátero Ferrifero, MG e seu potencial para adsorção e desorção de metais traço. Tese (Doutorado). Ouro Preto: Departamento de Geologia - UFOP.

Bohrer, A. F. (2011). Ouro Preto: um novo olhar. São Paulo: Scortecci.

Borba, R. P., Figueiredo, B. R., Rawlins, B., Matschullat, J. (2000). Arsenic in water and sediment in the Iron Quadrangle, State of Minas Gerais, Brazil. Applied Geochemistry, 30(3), 558-561.

Canadian Council of Ministers of the Environment (CCME). (2003). Protocol for the derivation of Canadian sediment quality Guidelines for the protection of aquatic life. Environment Canada, Guidelines Division Technical
Secretariat of the CCME Task Group on Water Quality Guidelines. Ottawa: EPC-98E.

Centro de Tecnologia Mineral (CETEM). (2012). População se mobiliza contra efeitos negativos da exploração de ferro e bauxita em Ouro Preto (MG). Disponível em: $<$ http://verbetes. cetem.gov.br/verbetes/ExibeVerbete. aspx? verid=123>.

Acesso em: 8 nov. 2016.

Cole, S. (1998). The emergence of treatment wetlands. Environmental Science \& Technology, 32, 218A-223A. https://doi.org/10.1021/es9834733

Companhia Ambiental do Estado de São Paulo (CETESB). (2001). Relatório de Estabelecimento de Valores Orientadores para Solos e Águas Subterrâneas no Estado de São Paulo. São Paulo: CETESB.

Costa, A. T. (2001). Geoquímica das águas e sedimentos da bacia do rio Gualaxo do Norte, leste-sudeste do Quadrilátero Ferrífero (MG): Estudo de uma área afetada por atividades de extração mineral. Dissertação (Mestrado). Ouro Preto: Departamento de Geologia - UFOP.

Costa, A. T. (2007). Registro histórico de contaminação por metais pesados, associados à exploração aurífera no alto e médio curso da bacia do ribeirão do Carmo, QF: Um estudo de sedimentos de planícies de inundação e terraços aluviais. Tese (Doutorado). Ouro Preto: Departamento de Geologia-UFOP.

Costa, A. T. C., Nalini Jr., H. A., Castro, P. T. A., Tatumi, S. H. (2010). Análise estratigráfica e distribuição do arsênio em depósitos sedimentares quaternários da porção sudeste do Quadrilátero Ferrífero, bacia do ribeirão do Carmo, MG. REM: Revista Escola de Minas, 63(4), 703-714. http://dx.doi. org/10.1590/S0370-44672010000400017

Costa, A. T., Nalini Jr., H. A., Castro, P. T. A., Lena, J. C., Morgenstern, P., Friese, K. (2006). Sediment contamination in floodplains and alluvial terraces as an historical record of gold exploitation in the Carmo River basin, Southeast Quadrilátero Ferrífero, Minas Gerais, Brazil. Acta Hydrochimica et Hydrobiologica, 34, 245-256. https://doi.org/10.1002/ aheh. 200400625

Departamento Nacional de Produção Mineral (DNPM). (1962). Carta Topográfica Dom Bosco (MG). SF. 23-E-I-4-SO e Ouro Branco (MG). SF.23-E-III-2-NO. Escala 1:25.000.

Departamento Nacional de Produção Mineral (DNPM). (2013). Sumário Mineral. Disponível em: <http://www. dnpm.gov.br/dnpm/sumarios/sumario-mineral-2013>.

Acesso em: 8 nov. 2016. 
Eleutério, L. (1997). Diagnóstico da Situação Ambiental da Cabeceira da Bacia do Rio Doce, MG, no Âmbito das Contaminações por Metais Pesados, em Sedimentos de Fundo. Dissertação (Mestrado). Ouro Preto: Departamento de Geologia - UFOP.

Garcia-Ordiales, E., Loredo, J., Covelli, S., Esbrí, J. M., Millán, R., Higueras, P. (2017). Trace metal pollution in freshwater sediments of the world's largest mercury mining district: sources, spatial distribution, and environmental implications. Journal of Soils and Sediments. http://dx.doi. org/10.1007/s11368-016-1503-5

Gleyzes, C., Tellier, S., Astruc, M. (2002). Fractionation studies of trace elements in contaminated soil and sediments: a review of sequential extraction procedures. Trends in Analytical, 21(6-7), 451-467. https://doi.org/10.1016/ S0165-9936(02)00603-9

Hudson-Edwards, K. A., Macklin, M. G., Curtis, C. D., Vaughan, D. J. (1998). Chemical remobilization of contaminant metals within flood plain sediments in a incising river system: implications for dating and chemostratigraphy. Earth Surface Processes and Landforms, 23, 671-684. https://doi. org/10.1002/(SICI)1096-9837(199808)23:8\%3C671::AIDESP871\%3E3.0.CO;2-R

Instituto de Geociências Aplicadas (IGA). (1981a). Carta topográfica Cachoeira do Campo SF-23-XA-III-4-NO MI-2573/4-NO. Escala 1:25.000. Belo Horizonte: DSG.

Instituto de Geociências Aplicadas (IGA). (1981b). Carta topográfica Itabirito. SF-23-X-AIII-3-NE MI-2573/3-NE. Escala 1:25.000. Belo Horizonte: DSG.

Instituto de Geociências Aplicadas (IGA). (1981c). Carta topográfica Miguel Burnier. SF-23X-A-III-3-SE MI-2573/3-SE. Escala 1:25.000. Belo Horizonte: DSG.

Lobato, L., Baltazar, O. F., Reis, L. B. (2005). Projeto Geologia do Quadrilátero Ferrífero - Integração e Correção Cartográfica em SIG. Escala 1:50.000. Belo Horizonte: Companhia de Desenvolvimento Econômico de Minas Gerais.

MacDonald, D. D., Ingersoll, C. G., Berger, T. A. (2000). Development and evaluation of consensus - based sediment quality guidelines for freshwater ecosystems. Archives of Environmental Contamination and Toxicology, 39, 20-31.

Martins, G. R., Kashimoto, E. M., Tatumi, S. H. (1999). Datações Arqueológicas em Mato Grosso do
Sul. Revista do Museu da Arqueologia e Etnologia, 9, 73-93. http://dx.doi.org/10.11606/issn.2448-1750. revmae.1999.109343

Matschullat, J., Borba, R. P., Deschamps, E., Figueiredo, B. R., Gabrio, T., Schwenk, M. (2000). Human and environmental contamination in the Iron Quadrangle, Brazil. Applied Geochemistry, 15, 181-190. https://doi.org/10.1016/ S0883-2927(99)00039-6

Miall, A. D. (1978). Lithofacies types and vertical profile models in braided river deposits: a summary. In: A. D. Miall (Ed.), Fluvial sedimentology (Mem 5, p. 597-604). Calgary: Canadian Society of Petroleum Geologists.

Miall, A. D. (1988a). Facies architecture in clastic sedimentary basins. In: K. Kleinspehn, C. Paola (Eds.), New perspectives in basin analysis (p. 67-81). Nova York: Springer-Verlag.

Miall, A. D. (1988b). Reservoir heterogeneities in fluvial sandstones: lessons from outcrop studies. American Association of Petroleum Geology Bulletin, 72, 682-697.

Miall, A. D. (1992). Alluvial Deposits. In: R. G. Walker, N. P. James (Eds.), Facies Models: response to sea level change. Stittsville: Geological Association of Canada.

Miall, A. D. (2006). The geology of fluvial deposits sedimentary facies, basin analysis and petroleum geology. Berlim: Springer.

Oliveira, M. R. (1998). Investigação por Contaminação por Metais Pesados no Sedimento de Corrente e Água do Parque Estadual do Itacolomi, Minas Gerais e Arredores. Dissertação (Mestrado). Ouro Preto: Departamento de Geologia - UFOP.

Ontario Ministry of the Environment and Energy (OMEE). (1993). Guidelines for the protection and management of aquatic sediment quality in Ontario. Toronto: Ontario Ministry of the Environment and Energy.

Rauret, G., López-Sanchez, J. F., Luck, D., Yli-Halla, M., Muntau, H., Quevauviller, Ph. (2001). The Certification of the extractable contents (mass fractions) of $\mathrm{Cd}, \mathrm{Cr}, \mathrm{Cu}$, $\mathrm{Ni}, \mathrm{Pb}$ e $\mathrm{Zn}$ in freshwater sediment following sequential extraction procedure - BCR 701 . BCR information reference material.

Reimann, C., Caritat P. (1998). Chemical elements in the environment: Factsheets for the geochemist and environmental scientist. Berlim: Springer-Verlag Berlin Heidelberg. 
Reimann, C. Filzmoser, P., Garrett, R. G. (2005). Background and threshold: critical comparison of methods of determination. Science of the Total Environment, 346, 1-16. https://doi. org/10.1016/j.scitotenv.2004.11.023

Ribeiro, R. K. (1998). Mineralogia, Geoquímica e Gênese das ocorrências Auríferas no Flanco Norte do anticlinal de Mariana, Quadrilátero Ferrifero: Uma Nova Tipologia de Minério denominada Bugre. Dissertação (Mestrado). Brasília: Instituto de Geociências - UNB.

Rodrigues, A. S. L. (2012). Caracterização da bacia do rio Gualaxo do Norte, Mg, Brasil: Avaliação geoquímica ambiental e proposição de valores de background. Tese (Doutorado). Ouro Preto: Departamento de Geologia - UFOP.

Rodrigues, A. S. L., Malafaia, G., Costa, A. T. Nalini Jr., H. A. (2013). Evaluation of the mineral exploration influence on sediment composition in the Gualaxo do Norte River Basin (MG-Brazil) based on geochemical and stratigraphic data. Environmental Earth Science, 68, 965-972. https://doi. org/10.1007/s12665-012-1799-4

Rodrigues, A. S. L, Malafaia, G., Costa, A. T., Nalini Jr., H. A. (2014). Iron ore mining promotes iron enrichment in sediments of the Gualaxo do Norte River basin, Minas Gerais State, Brazil. Environmental Earth Science, 71, 4177-4186. https://doi.org/10.1007/ s12665-013-2808-y

Roeser, H. M. P., Roeser, P. A. (2010). O Quadrilátero Ferrífero - MG, Brasil: aspectos sobre sua história, seus recursos minerais e problemas ambientais relacionados. Geonomos, 18(1), 33-37. http://dx.doi.org/10.18285/ geonomos.v18i1.67
Sakan, S., Dević, G., Relić, D., Andelković, I., Sakan, N., Dordević, D. (2015). Evaluation of sediment contamination with heavy metals: the importance of determining appropriate background content and suitable element for normalization. Environmental Geochemistry and Health, 37, 97-113. https://doi. org/10.1007/s10653-014-9633-4

Selmi, M., Lagoeiro, L. E., Endo I. (2009). Geochemistry of hematitite and itabirite, Quadrilátero Ferrífero, Brazil. REM: Revista Escola de Minas, 62(1), 35-43. http://dx.doi. org/10.1590/S0370-44672009000100006

Smith, S. L., MacDonald, D. D., Keenleyside, K. A., Ingersoll, C. G., Field, J. (1996). A preliminary evaluation of sediment quality assessment values for freshwater ecosystems. Journal of Great Lakes Research, 22, 624-638. https://doi. org/10.1016/S0380-1330(96)70985-1

Tukey, J. W. (1977). Exploratory data analysis. Reading (MA): Addison-Wesley.

Vicq, R. F. C. (2015). Mapeamento geoquímico e estabelecimento de valores de referência (background) de sedimentos fluviais do Quadrilátero Ferrifero. Tese (Doutorado). Ouro Preto: Departamento de Geologia-UFOP.

Vicq, R., Matschullat, J., Leite, M. G. P., Nalini Jr., H. A., Mendonça, F. P. C. (2015). Iron Quadrangle stream sediments, Brazil: geochemical maps and reference values. Environmental Earth Sciences, 74(5), 4407-4417. https:// doi.org/10.1007/s12665-015-4508-2

Walker, R. G. (1992). Facies, Facies Models and Modern Stratigraphic Concepts. In: R. G. Walker, N. P. James (Eds.), Facies models: response to sea level change. Stittsville: Geological Association of Canada. 